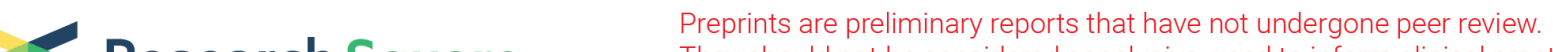 Research Square They should not be considered conclusive, used to inform clinical practice, or referenced by the media as validated information.
}

\section{Bmal1- and Per2-Mediated Regulation of the Osteogenic Differentiation and Proliferation of Mouse BMSCs by Modulating the Wnt/ $\beta$-catenin Pathway}

\section{Jiawen Zheng ( $\nabla$ zhjw1107@163.com )}

Sichuan University West China Hospital of Stomatology: Sichuan University West China College of Stomatology https://orcid.org/0000-0001-5551-7398

\section{Lanxin Zhang}

Sichuan University Huaxi College of Stomatology: Sichuan University West China College of Stomatology

\section{Zhen Tan}

Sichuan University Huaxi College of Stomatology: Sichuan University West China College of

Stomatology

\section{Yuhong Wang}

Sichuan University Huaxi College of Stomatology: Sichuan University West China College of Stomatology

\section{Qing Zhao}

Sichuan University Huaxi College of Stomatology: Sichuan University West China College of

Stomatology

Chenxiaoxue Zhang

Sichuan University Huaxi College of Stomatology: Sichuan University West China College of Stomatology

\section{Xiaoyu Wei}

Sichuan University Huaxi College of Stomatology: Sichuan University West China College of Stomatology

\section{Yuqing Yang}

Sichuan University Huaxi College of Stomatology: Sichuan University West China College of Stomatology

\section{Research}

Keywords: BMSCs, CCGs, proliferation, osteogenic differentiation, aging 
DOI: https://doi.org/10.21203/rs.3.rs-510667/v1

License: (a) (i) This work is licensed under a Creative Commons Attribution 4.0 International License. Read Full License 


\section{Abstract}

\section{Background}

Bmal1 and Per2 are the core components of the circadian clock genes(CCGs). Bmal1 ${ }^{-/-}$mice exhibit premature aging, as indicated by hypotrichosis and osteoporosis, with a loss of proliferation ability. The same occurs in Per2 ${ }^{-1-}$ mice, albeit to a less severe degree. However, whether the effects of Bmal1 and Per2 on proliferation and osteogenic differentiation are synergistic or antagonistic remains unclear. Thus, our study aimed to explore the effects and specific mechanism.

Materials and methods

Lentiviral and adenoviral vectors were constructed to silence or overexpress Bmal1 or Per2 and MTT, flow cytometry, RT-qPCR, WB, immunohistochemistry, alizarin red staining and ChIP-Seq analyses were applied to identify the possible mechanism.

Results

The successful knockdown and overexpression of Bmal1/Per2 were detected by fluorescence microcopy. Flow cytometry found out that Bmal1 or Per2 knockdown resulted in G1-phase cell cycle arrest. RT-qPCR showed the different expression levels of Wnt-3a, c-myc1 and axin2 in the Wnt/ $\beta$-catenin signaling pathway as well as the gene expression change of Rora and Rev-erba. Meanwhile, Related proteins such as $\beta$-catenin, TCF-1, and P-GSK-3 $\beta$ were detected. ALP activity and the amount of mineral nodules were compared. ChIP-Seq results showed the possible mechanism.

\section{Conclusions}

Bmal1 and Per2, as primary canonical clock genes, showed synergistic effects on the proliferation and differentiation of BMSCs. They would inhibit the Wnt/ $\beta$-catenin signaling pathway by downregulating Rora expression or upregulating Rev-erba expression, both of which were also key elements of CCGs. And this may be the mechanism by which they negatively regulate the osteogenic differentiation of BMSCs.

\section{Introduction}

Bone density and bone mass decrease during aging, which increases the risk of fracture and negatively affects the quality of life of adult . ${ }^{1}$ Aging-related changes in the bone are derived from bone marrow mesenchymal stem cells (BMSCs), whose proliferation and osteogenic differentiation capacity decreases over time. ${ }^{2}$

The roles of circadian clock genes in aging have recently attracted increasing attention. A related study showed that knockout of core circadian clock genes (CCGs) caused significant premature aging.

Rescuing gene expression reversed the premature aging changes. ${ }^{3,4}$ The CCGs in mammals include brain Loading [MathJax]/jax/output/CommonHTML/jax.js d 2 (Per2), circadian locomotor output cycles kaput (Clock), 
cryptochrome (Cry), retinoid acid receptor-related orphan receptor Rora and Rev-erba, which regulate circadian rhythm through an oscillating expression system, establishing a negative feedback network. ${ }^{5-7}$ In this feedback network, Bmal1-Clock dimer can bind to Per promoter ${ }^{6}$, which interferes with the transcription activity of Bmal1-Clock after translation, while Rora can activate the transcription of Bmal1 and Rev-erba can inhibit the transcription of Bmal17. The disruption of the biological rhythms can cause aging. Some research has shown that $\mathrm{Bmal1}^{-/-}$mice underwent premature aging, resulting in hypotrichosis and osteoporosis. Similar phenomena were found in Per2 ${ }^{-/-}$mice, albeit to a less severe degree. ${ }^{8}$ Other studies also found that Bmal1 or Per2 can regulate the proliferation and osteogenic differentiation ability of BMSCs. ${ }^{9-11}$ However, a consensus regarding whether their effects are synergistic or antagonistic has not yet been reached, ${ }^{12}$ which makes our study particularly significant.

The Wnt/ $\beta$-catenin pathway ${ }^{13}$ plays a pivotal role in the regulation of proliferation and osteogenic differentiation of BMSCs by inducing the formation of osteoblasts and repressing the differentiation of osteoclasts. ${ }^{14}$ Binding sites of Bmal1 are found in the coding sequence of many genes in the Wnt/ $\beta$ catenin pathway, such as Wnt10a, $\beta$-catenin, and T-cell-specific transcription factor-3 (TCF3). ${ }^{15-17}$ However, whether there is some interaction between CCGs and the Wnt/ $\beta$-catenin pathway remains poorly understood. Furthermore, Rora and Rev-erba not only constitute a closed loop with Bmal1 through mutual regulation but also regulate the downstream target genes of the Wnt/ $\beta$-catenin pathway. ${ }^{16,17}$ Therefore, Rora and Rev-erba may be critical factors in the regulation of the Wnt/ $\beta$-catenin pathway by Bmal1 and Per2. In summary, we proposed the following hypothesis: Bmal1 and Per2 could regulate the aging of BMSCs by altering cell proliferation and osteogenic differentiation through the Wnt/ $\beta$-catenin pathway. In addition, there might be some interaction between Bmal1 and Per2.

In this study, we altered the expression of Bmal1 and/or Per2 by virus transfection, then observed the expression of osteogenic marker genes such as alkaline phosphatase (Alp), osteocalcin (Ocn), and runtrelated transcription factor 2 (Runx2). We also detected the activity of ALP, the proliferation ability of BMSCs and the expression changes in Rora and Rev-erba as well as the core molecules of the Wnt/ $\beta$ catenin pathway, including Wingless Int1 3a (Wnt3a ), Cell-myc1 (C-myc), Axin2, $\beta$-catenin, T-cell-specific transcription factor 1 (TCF1), and phosphorylated glycogen synthase kinase-3 $\beta$ (P-GSK-3), after altering the expression of Bmal1 and/or Per2. Finally, we identified the target genes and pathways of Bmal1 and Per2 by chromatin immunoprecipitation and high-throughput sequencing (ChIP-Seq) to verify the role of the Wnt/ $\beta$-catenin pathway and explore other possible mechanisms. Our research aimed to find new targets for the treatment and prevention of bone senescence or osteoporosis.

\section{Materials And Methods \\ 2.1 Cell culture}

BMSCs were obtained from four-week-old C57BL/6 male mice. After passaging the cells twice, the thirdLoading [MathJax]/jax/output/CommonHTML/jax.js Clone, USA) with $10 \%$ fetal bovine serum, $100 \mathrm{U} / \mathrm{ml}$ penicillin 
and $100 \mathrm{mg} / \mathrm{ml}$ streptomycin and incubated at $37^{\circ} \mathrm{C}$ with an atmosphere of $95 \%$ relative humidity and $5 \%$ $\mathrm{CO}_{2}$. When the cells reached approximately $80 \%$ confluence, $0.25 \%$ trypsin in $0.01 \%$ ethylenediaminetetraacetic acid (EDTA) was used to detach the cells, which were passaged to the next generation. Mesenchymal stem cells (MSCs) were identified by immunohistochemistry as CD29(+), Stro$1(+)$, CD45(-) and CD34(-) cells. In our study, we conducted experiments with fifth-generation cells.

\subsection{Construction of BMSC line with shRNA infection}

Our study had 9 groups as follows: blank control, Bmal1 knockdown, Bmal1 empty vector control, Per2 knockdown, Per2 overexpression, Per2 empty vector control, Bmal1 knockdown and Per2 knockdown, Bmal1 knockdown and Per2 overexpression, Bmal1 empty vector and Per2 empty vector control.

Isolated BMSCs were seeded in 24-well plates at $5 \times 10^{5}$ cells per well in basic media. Bmal1 shRNA lentivirus (Arntl shRNA, purchased from Hanheng Bio, Shanghai, China) or Bmal1 empty lentivirus (PHBLV-U6-ZsGreen-Puro) was added to the cells at a multiplicity of infection (MOI) of 20 after the cell confluence reached $70 \%$. The medium was replaced with a-MEM medium containing $2 \mu \mathrm{g} / \mathrm{ml}$ puromycin

after another 24 hours. Green fluorescence was observed under an inverted fluorescence microscope (Olympus IX70, Japan). The cells were passaged with transfection efficiency over $80 \%$ and cryopreserved for the next experiments.

The 9 groups aforementioned were created through different transfection measures by adding both shRNA and empty vectors at an $\mathrm{MOI}$ of 20 and replacing the medium with basic medium after 24 hours of incubation. Red fluorescence was observed under an inverted fluorescence microscope 48 hours after transfection. Western blot analysis was also applied to calculate the efficiency of infection. In these analyses, anti-BMAL1 (diluted to 1:500), anti-PER2 (diluted to 1:500) and F-actin (diluted to 1:1000) were utilized as the primary antibodies, while goat anti-rabbit IgG (diluted to 1:1000) was utilized as the secondary antibody.

\subsection{Methyl thiazolyl tetrazolium (MTT)-based detection of proliferative activity 20}

After transfection with the corresponding lentivirus or adenovirus, cells in the 9 groups were plated and cultured in 96-well plates. Ten microliters of PBS solution containing $5 \mathrm{mg} / \mathrm{ml}$ MTT was added to the wells of each group and allowed to incubate for 24 hours. Six hours after incubation with MTT, $150 \mu$ of dimethyl sulfoxide (DMSO) was added to each well, and the plates were vibrated on a table concentrator for 10 minutes. We measured the optical density at $490 \mathrm{~nm}$ (OD490) at 24, 48 and 72 hours.

\subsection{Flow cytometry detection of BMSC proliferation}

The cells from passage 5 in 9 groups were detached from the 6-well plates with trypsin and ethylenediaminetetraacetic acid. The samples were washed twice with PBS and centrifuged at $1000 \mathrm{rpm}$ for 5 minutes. Then, the samples were placed in $70 \%$ alcohol and incubated at $-20^{\circ} \mathrm{C}$ for at least 2 hours

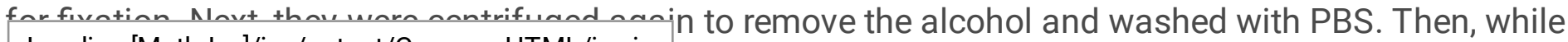
Loading [MathJax]/jax/output/CommonHTML/jax.js 
shielded from light, they were stained with propidium iodide $(\mathrm{PI})$, incubated in a water bath at $37^{\circ} \mathrm{C}$ for 30 minutes and then incubated with RNase at $4^{\circ} \mathrm{C}$. The cell density was adjusted to approximately $1 \times 10^{6}$ cells/ml for detection. The following formula was used to calculate the S-phase fraction (SPF) and DNA proliferation index:

$\operatorname{SPF}(\%)=S(G 0 / G 1+G 2 / M) * 100 \%$

DNA proliferation index (\%)

$=(\mathrm{S}+\mathrm{G} 2 / \mathrm{M}) /(\mathrm{G} 0 / \mathrm{G} 1+\mathrm{S}+\mathrm{G} 2 / \mathrm{M}) * 100 \%$

\subsection{Real-time reverse transcription polymerase chain reaction (RT-PCR)}

After viral transfection, the cells in the 9 groups were cultured in 6-well plates with osteogenic induction medium (OS medium), which contained $12 \mathrm{mmol} / \mathrm{L} \beta$-glycerophosphate, $1 * 10^{-} 8 \mathrm{~mol} / \mathrm{L}$ dexamethasone, $0.05 \mathrm{mmol} / \mathrm{L}$ vitamin $C$ and $10 \%$ fetal bovine serum. Approximately $1 * 10^{5}$ cells were plated in each well. The medium was changed after 2 days. The expression of osteogenesis-related genes, such as ALP, OCN, and Runx2, was detected after 7 days and 14 days. Total RNA was extracted with the Simply P total RNA extraction kit. To ensure high purity, assessment of the 20- $\mu$ reaction mixture products was performed with an ABI PRISM 7300 real-time system with glyceraldehyde-3-phosphate dehydrogenase (GAPDH) Factin as an internal reference.(Table 1 )

Table 1

Primer sequences for RT-qPCR. Abbreviations: ALP: Alkaline phosphatase; RUNX2: Runt-related transcription factor 2; OCN: Osteocalcin; Wnt3a: Wingless Int13a; C-myc: Cell-myc; Ror-a: retinoid acid receptor related orphan receptor $\mathrm{a}$.

\begin{tabular}{|llll|}
\hline Gene & $\begin{array}{l}\text { Fragment size } \\
(\mathrm{bp})\end{array}$ & Forward primer & Reverse primer \\
\hline ALP & $140 \mathrm{bp}$ & ATAACGAGATGCCACCAGAGG & TTCCACATCAGTTCTGTTCTTCG \\
\hline RUNX2 & $190 \mathrm{bp}$ & CTACCCAGCCACCTTTACCTAC & GAACTGATAGGATGCTGACGAAG \\
\hline OCN & $147 \mathrm{bp}$ & AGGAGGGCAATAAGGTAGTGAAC & AGGCGGTCTTCAAGCCATAC \\
\hline Actin & $263 \mathrm{bp}$ & GAGACCTTCAACACCCCAGC & ATGTCACGCACGATTTCCC \\
\hline Wnt3a & $117 \mathrm{bp}$ & GCACCACCGTCAGCAACA & AGCGTGTCACTGCGAAAGC \\
\hline C-myc & $196 \mathrm{bp}$ & CACAACTACGCCGCACCC & GCTTCAGCTCGTTCCTCCTCT \\
\hline Axin2 & $174 \mathrm{bp}$ & ACCGTGGTTGGCTTGTCC & GGATAACTCGCTGTCGTTGG \\
\hline Rora & $163 \mathrm{bp}$ & GGATGTGCCGTGCCTTTG & GCGATTTCGTCTTCGGTCA \\
\hline $\begin{array}{l}\text { Rev- } \\
\text { erba }\end{array}$ & $160 \mathrm{bp}$ & CCTTCCTCCTACCCGCCTAC & GAACATTCTTGGTGTTGCCTTG \\
\hline
\end{tabular}




\subsection{Western blot analysis of related proteins in the Wnt/ $\beta$ - catenin signaling pathway}

To extract protein from passage 5 BMSCs cultured for 7 days and for 14 days, the cells were washed in ice-cold PBS 3 times and sufficiently lysed in radioimmunoprecipitation assay (RIPA) lysis buffer. After centrifugation at $12000 \mathrm{rpm}$ for 15 minutes at $4^{\circ} \mathrm{C}$ the liquid supernatant was collected for the protein concentration assessment using a bicinchoninic acid (BCA) protein assay kit. Sodium dodecyl sulfonatepolyacrylate gel electrophoresis (SDS-PAGE) was performed to separate the proteins, which were transferred to polyvinylidene fluoride (PVDF) membranes. Then, the membranes were blocked and incubated with primary antibodies and then the secondary antibody. The chemiluminescence method was used to detect the immunoreactive proteins, and the band intensities were analyzed by a gel documentation system.

\subsection{Analysis of ALP activity.}

After BMSCs were transfected with the corresponding virus and allowed to undergo osteogenic induction for 7 days (with medium replacement every two days), we harvested and lysed the cells with $10 \mathrm{mM}$ Tris$\mathrm{HCl}$ and $0.1 \%$ Triton $\mathrm{X}-100(\mathrm{pH} 7.4)$. The supernatant obtained through centrifugation was stained according to the instructions of the ALP Detection Kit. ALP activity, expressed as units/L protein, was calculated by measuring the absorbance at $510 \mathrm{~nm}$ on a spectrophotometer.

\subsection{Immunohistochemistry}

The cells were lysed and adjusted to approximately $2 \times 10^{4}$ cells $/ \mathrm{ml}$ in complete medium. The cells attached on the 12-well plates for 30 minutes were cultured in $37^{\circ} \mathrm{C}$ with $5 \% \mathrm{CO}_{2}$. The cell discs were washed in PBS twice and bathed in 4\% Paraformaldehyde 20 minutes. Then the discs were soak in $0.5 \%$ Triton X-100 for 20 minutes and washed by PBS for three times. And then they were bathed in $3 \% \mathrm{H}_{2} \mathrm{O}_{2}$ for 15 minutes. The membranes were incubated with primary antibodies and then the secondary antibody. Generally DAB stain, haematoxylin slightly stain, alcohol dehydration, xylene transparent and neutral balata fixation.

\subsection{Alizarin red staining}

The BMSCs were cultured in OS medium after 7 days and 14 days and the cell density was adjusted to approximately $2 \times 10^{4} \mathrm{cells} / \mathrm{ml}$ in complete medium. The cells attached on the 24-well plates for 30 minutes were cultured in $37^{\circ} \mathrm{C}$ with $5 \% \mathrm{CO}_{2}$. The cell discs were washed in PBS twice and bathed in $4 \%$ Paraformaldehyde 20 minutes. Then the discs were stained by alizarin red for 30 minutes and washed by distilled water.

\subsection{ChIP-Seq and data analysis}

BMSCs were cross-linked with $1 \%$ formaldehyde at room temperature for 10 minutes, and the reaction was terminated by the addition of alvcine. The collected cells were lysed (50 mM Tris- $\mathrm{HCl}, \mathrm{pH} 7.4 ; 10 \mathrm{mM}$ Loading [MathJax]/jax/output/CommonHTML/jax.js 
EDTA; 1\% SDS; and protease inhibitor) and sonicated. Anti-BMAL1 and anti-PER2 antibodies were used to precipitate the corresponding DNA fragments. Bound DNA was incubated at $65^{\circ} \mathrm{C}$ overnight to reverse the cross-links. After the DNA purity and concentration was measured, the target gene was amplified by qPCR. We performed high-throughput sequencing on an Illumina HiSeq platform and analyzed the relevant data.

\subsection{Statistical analysis}

The data are presented as the mean \pm standard error of the mean. Significance was determined using one-way analysis of variance and the Student-Newman-Keuls (SNK) test for multiple comparisons with SPSS 19.0, with $\mathrm{P}<0.05$ as the cutoff.

\section{Results}

\subsection{Altered expression of Bmal1 and/or Per2 at the mRNA and protein levels after transfection with viral vectors.}

Green and red fluorescence protein expression were detected by fluorescence microcopy, confirming the knockdown of Bmal1 and the knockdown/overexpression of Per2 (Figure 1A). The protein expression level was in accordance with gene expression level for each gene (Figure 1B, C).

\subsection{The growth curve}

The growth curve(Figure 2A)according to the OD490 values obtained through the MTT assay indicated the proliferation rates of the different groups. The proliferative activity of cells overexpressing Per2 increased compared to that of control cells, and accordingly, the survival rate of this group (group 5) was the highest among all groups. When we inhibited Bmal1 (group 2), Per2 (group 4) or both (group 7), the proliferation rate decreased significantly compared with that in the groups transfected with an empty viral vector (groups 3, 6, and 9).

\subsection{The proliferation rates of different groups evaluated by flow cytometry.}

The percentage of cells distributed in the $\mathrm{G} 0$ phase, $\mathrm{G} 1$ phase, $\mathrm{G} 2$ phase, $\mathrm{S}$ phase and $\mathrm{M}$ phase reflects the cell activity to some degree. The flow cytometry results(Figure 2B) showed that cells overexpressing Per2 had the greatest proliferative activity, with the highest SPF value and PI staining rate. Cells with knockdown of Bmal1, Per2 or both exhibited a lower proliferation rate than their matched control groups.

\subsection{Expression of classical Wnt/ $\beta$-catenin signaling pathway-related genes.}

The difference in the expression of Wnt-3a between the Bmal1 and Per2 knockdown group and the matched empty vector group was significant, specifically showing that suppressing Bmal1 and Per2 simultaneously increased the levels of Wnt-3a, c-myc1 and axin2. Knockdown of Bmal1 alone increased 
the expression of c-myc1 and axin2, and the effect on axin2 was increased with combined knockdown of Per2 (Figure 3A).

\subsection{Expression level of Wnt/ $\beta$-catenin signaling pathway-related proteins.}

It was concluded that the levels of $\beta$-catenin, TCF-1, and P-GSK-3 $\beta$ (Figure 3B)increased under four different conditions in our experiment: Bmal1 knockdown, Per2 knockdown, Bmal1 knockdown/Per2 knockdown and Bmal1 knockdown/Per2 overexpression. The expression level in the Bmal1 knockdown/Per2 overexpression group was higher than that in the Per2 overexpression group, and the difference was statistically significant. The probable mechanism is that the expression of Per2 is promoted when Bmal1 is suppressed. The effects of Per2 overexpression were strengthened in the combination group, leading to increased expression of proteins related to the $\mathrm{Wnt} / \beta$-catenin signaling pathway.

\subsection{Changes in osteogenic marker gene expression in each group after osteogenic induction.}

Our previous research explored the effect of Bmal1 knockdown, Per2 knockdown and Bmal1 knockdown/Per2 knockdown on the osteogenic differentiation ability of BMSCs; we found that Bmal1 and Per2 negatively and synergistically regulated this process. ${ }^{18}$ Therefore, we designed an experiment to assess the osteogenic differentiation capability of BMSCs in different groups, including Bmal1 knockdown, Per2 overexpression, and Bmal1 knockdown/Per2 overexpression groups, to verify the previous results.

\subsubsection{ALP activity in each group after 7 days of osteogenic induction.}

In the Bmal1 knockdown group, ALP activity, an early osteogenic differentiation marker, was enhanced compared with that in the empty control group (Figure 4D) but declined in the Per2 overexpression group. The activity of ALP in the Bmal1 knockdown/Per2 overexpression group was also elevated and was even higher than that in the Bmal1 knockdown group. There were no significant differences between the control groups (group 1, group 3, group 6, and group 9), which shows that viral transfection had no impact on ALP activity.

\subsubsection{Expression of osteogenic differentiation-related genes.}

The mRNA expression levels of Alp, Runx2 and Ocn in the Bmal1 knockdown group exceeded those in the control group but were lower than those in the Bmal1 knockdown/Per2 overexpression group. Bmal1 knockdown/Per2 knockdown had significantly stronger effects than empty control transfection after 7 days of osteogenic induction (Figure 4A-C). The differences in Ocn expression in each group detected 14 days later were in accordance with the result observed after 7 days of osteogenic induction (Figure 5A). The protein expression levels were still in accordance with the mRNA expression levels at these time points. 


\subsubsection{The gene expression of Rora}

In the four experimental groups, Bmal1 knockdown, Per2 knockdown, Bmal1 knockdown/Per2 knockdown and Bmal1 knockdown/Per2 overexpression, the expression of Rora was remarkably higher than that in the corresponding empty control groups; in the Per2 overexpression group, the outcome was the opposite (Figure 5B). Inhibiting both Bmal1 and Per2 had a greater effect than inhibiting Per2 alone. To our surprise, the effect in the Bmal1 knockdown/Per2 knockdown and Bmal1 knockdown/Per2 overexpression groups was greater than that in the Bmal1 knockdown group. There were no significant differences among the blank control group and the other control groups transfected with empty vectors, indicating that viral transfection exerted no impact on the expression of Rora. The protein and gene expression trends of Rora were consistent.

\subsubsection{The gene expression of Rev-erba}

In the four experimental groups, Bmal1 knockdown, Per2 knockdown, Bmal1 knockdown/Per2 knockdown and Bmal1 knockdown/Per2 overexpression, the expression of Rev-erba decreased compared with that in the blank control group, but the difference between the Per2 knockdown group and the control group was not significant (Figure 5C). In addition, knockdown of both Bmal1 and Per2 led to a much lower expression level of Rev-erba than did knockdown of Bmal1 or Per2 alone, verifying their synergistic effects. Overexpression of Per2 increased the expression of Rev-erba, which contrasted with the effect of combined Bmal1 knockdown/Per2 overexpression. The protein expression trend of Rev-erba in these groups was in accordance the mRNA expression trend.(Figure 5D,5E)

\subsection{Immunohistochemistry}

blank control, Bmal1 knockdown, Bmal1 empty vector control, Per2 knockdown, Per2 overexpression, Per2 empty vector control, Bmal1 knockdown and Per2 knockdown, Bmal1 knockdown and Per2 overexpression, Bmal1 empty vector and Per2 empty vector control.

The ALP activity of Bmal1 knockdown group was enhanced compared with the control group, which indicated that Bmal1 had negative effect on osteogenic differentiation of BMSCs. The ALP activity decreased in Per2 overexpression group, which demonstrated Per2 could inhibit the osteogenic differentiation of BMSCs. Whether Per2 was overexpressed or suppressed, Bmal1 knockdown would facilitate bone mineralization.

\subsection{Alizarin red staining}

The results of alizarin red staining shows that the mineralized nodules were increased in Bmal1 knockdown and Per2 knockdown group compared with blank control. While inhibiting Bmal1 and Per2 simultaneously would enhance the positive effect.

\subsection{ChIP-Seq results}




\subsubsection{Gene Ontology (GO) functional analysis}

GO functional analysis results showed that Bmal1 and Per2 were mainly enriched in the protein binding molecular function category. The GO database was established by the Association of Gene Ontology, and $\mathrm{GO}$ analysis results are divided into three categories: ${ }^{21}$ molecular function, biological process and cellular components. The results obtained in vitro can be classified according to the results of the Bmal1 and Per2 ChIP-Seq experiments. Based on the identified regions in their genomes, these proteins have specific binding affinities and are mainly involved in regulating pathways related to cell proliferation, cell senescence, and osteogenic differentiation (Figure 6A, B).

\subsubsection{Kyoto Encyclopedia of Genes and Genomes (KEGG)}

KEGG analysis results revealed key genes related to BMAL1 and PER2 in the mouse genome. The constituents of the $\mathrm{Wnt} / \beta$-catenin pathway were detected in the region $2000 \mathrm{bp}$ away from the transcription site. The peak genes of Bmal1 in the Wnt/ $\beta$-catenin pathway included Wnt2b, Smad3, Axin2, Fzd6, Tcf712, etc. Similarly, the peak genes in Per2 included Wnt1, Wnt6, Wnt7b, and Smad3.

Furthermore, both Bmal1 and Per2 were notably enriched in the mTOR signaling pathway, ${ }^{22}$ Hippo signaling pathway and ubiquitin-mediated proteolysis pathway $(P<0.05$, Figure $6 C, 6 D)$, which means that the specific regulatory mechanisms may be coming into view.

\section{Discussion}

Osteoporosis due to aging has become a common bone and metabolic disease. Osteoporosis is mainly caused by disturbed proliferation and osteogenic differentiation of BMSCs. In our previous study, Bmal1 and Per2, the CCGs, were found to affect proliferation and osteogenic differentiation. $2^{2}$ As a supplement, in the present study we found that Bmal1 or Per2 knockdown resulted in G1-phase cell cycle arrest, giving rise to the loss of proliferation ability in BMSCs, which was the most well-established aging feature.

During this process, DNA was not produced and the cell did not proceed to the $\mathrm{S}$ phase, while suppressing Bmal1 and Per2 simultaneously generated stronger effects than inhibiting one of them separately. The results supported our hypothesis that Bmal1 and Per2 engaged in cross talk during cell proliferation.

Some research demonstrated that Bmal1 ${ }^{-/-}$mice had increased osteogenesis and bone-formation. ${ }^{23} \mathrm{And}$ some indicated that Bmal1 negatively affected mineral apposition rate of mice femur. ${ }^{24}$ In consistence, our results found that the osteogenic differentiation of BMSCs could be enhanced by inhibiting Bmal1. In our previous research, the capability of osteogenesis was elevated after inhibition of Per2. However, related research or projects in regard to the effect of Per2 on osteogenesis have not been reported. In this study, the expression levels of Alp, Runx2, and Ocn, which were important markers in osteogenic differentiation of BMSCs, decreased after Per2 overexpression. Our work further validated that Per2 performed a negative effect on osteogenesis. 
The oscillatory mechanisms underlying the CCGs has been unraveled. CLOCK and BMAL1, as a heterodimeric complex of two transcriptional activators, could bind to E-box enhancer elements and thereby activated the expression of Per1, Per2. ${ }^{25}$ Some research demonstrated Per2, Cry 1 mutant mice displayed an altered expression of genes regulated by BMAL1. ${ }^{26}$ It also has been reported that Per2 could bind to BMAL1 and interact with specific sites of BMAL1-CLOCK heterodimer. In the present study, Bmal1 played a synergistic effect with Per2 in the regulation of BMSCs might be explained by the mechanism mentioned above. Our previous study showed that the expression of Bmal1 changed with inhibition of Wnt/ $\beta$-Catenin pathway. It also demonstrated that Wnt/ $\beta$-Catenin pathway played a vital role in proliferation and osteogenesis differentiation of BMSCs. Recent research showed that Bmal1 had a synergistic effect on the aging of BMSCs directly or indirectly through the Wnt/ $\beta$-Catenin pathway. ${ }^{22-24} \beta-$ Catenin, the core signaling molecule of the $W n t / \beta$-catenin pathway, could reflect the degree of pathway activation. ${ }^{27}$ In our study, the level of $\beta$-catenin decreased with Per2 overexpression, while suppressing Bmal1 expression caused no significant change. We speculated that the $\mathrm{Wnt} / \beta$-catenin pathway could be activated under specific conditions and that different degrees of activation might lead to various biological effects. Some research has indicated that different expression levels of Bmal1 might have opposite effects ${ }^{28}$ on the Wnt/ $\beta$-catenin pathway, which explains our experimental results.

Furthermore, we conducted ChIP-Seq and KEGG analysis as a powerful tool to explore whether there were targets of Bmal1 and Per2 in the Wnt/ $\beta$-catenin pathway. Surprisingly, enrichment of Bmal 1 or Per2 in the Wnt/ $\beta$-catenin pathway was not significantly high, while enrichment of Hippo and mTOR signaling pathway and ubiquitin-proteasome proteolytic system was high, hence we hypothesized that the regulatory effects of Bmal1 and Per2 were achieved through multiple pathways crosslinked with Wnt/ $\beta$ catenin pathway. As vital downstream molecules of the Hippo signaling pathway ${ }^{29-31}$, YAP/TAZ isolate $\beta$ -

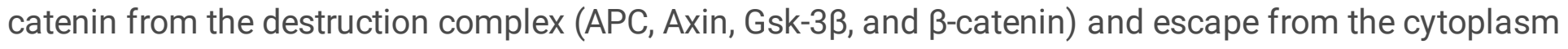
to the nucleus, which enhances the expression of downstream target genes and activates the Wnt/ $\beta$ catenin pathway. ${ }^{32.33}$ Some studies have shown that disturbing mTOR suppressed the growth of normal cells and tumor cells induced by the Wnt/ $\beta$-catenin signaling pathway. Changes in mTOR influenced the expression of the Wnt/ $\beta$-catenin signaling pathway to some degree. ${ }^{34191919191919191919}$ The ubiquitinproteasome proteolytic system plays an important role in the regulation of cell growth, proliferation, aging, and apoptosis. $\beta$-Catenin is degraded through its reaction with the E3 ubiquitin enzyme complex, ${ }^{35}$ which blocks the Wnt/ $\beta$-catenin signaling pathway. In summary, the $W n t / \beta$-catenin pathway crosstalks with the Hippo signaling pathway, mTOR and the ubiquitin-proteasome proteolytic system. Therefore, although direct enrichment of Bmal1 and Per2 in the Wnt/ $\beta$-catenin signaling pathway was not found, we still could speculate that Bmal1 and Per2 regulated the Wnt/ $\beta$-catenin pathway through other pathways, such as the Hippo, mTOR, and ubiquitin-proteasome pathways.

On the other hand, CLOCK-BMAL1/PER-CRY constitute a core feedback pathway, and the CLOCK-BMAL1 heterodimer activates the transcription of Rora and Rev-erba. RORa activates the transcription of Bmal1, while REV-ERBa downregulates BMAL1 through glucose synthesis kinase 3 (GSK-3ß)-mediated 
of the CCG system. GSK-3 $\beta$, a critical component of the Wnt/ $\beta$-catenin pathway, plays a negative role in the activation of this pathway by phosphorylating and promoting the degradation of $\beta$-catenin. ${ }^{37}$ Phosphorylated RORa can also repress the expression of the downstream target genes of $\beta$ catenin/TCF/LEF by binding to $\beta$-catenin in the nucleus. ${ }^{38} \mathrm{~A}$ recent study found that Rev-erba overexpression in BMSCs indirectly affected bone formation. ${ }^{39}$ These studies provide a clue that Rora and Rev-erba may act as mediators in the regulation of the Wnt/ $\beta$-catenin pathway by Bmal1 or Per2. Our study showed that Bmal1 or Per2 could negatively regulate the expression of Rora while upregulate the expression of Rev-erba. The effect could be enhanced by simultaneous inhibition of Bmal1 and Per2 expression. Conversely, Rev-erba suppressed osteogenic differentiation. Recent studies found that overexpression of Rora in preosteoblasts promoted bone formation and osteoblast differentiation. ${ }^{40}$ In addition, Rora reduced the destruction of bone tissue in human rheumatoid arthritis by inhibiting osteoclast differentiation. ${ }^{41}$ Animal experiments also showed that overexpressing Rora elevated the expression level of osteogenesis-related proteins such as ALP and OCN. ${ }^{42.43}$ Rora-knockout mice exhibited poor bone mineralization. ${ }^{44.45}$ These findings are in accordance with our results, indicating that Rora is involved in the positive regulation of the osteogenic differentiation of BMSCs. It has been found that decreasing RORa expression represses the expression of bone sialoprotein (BSP) and dentin matrix protein 1 (DMP-1) by impacting the downstream Wnt/ $\beta$-catenin pathway, thus affecting the osteogenic differentiation of BMSCs and bone mineralization. ${ }^{45}$ Our results also showed that the expression trend of Rora was in accordance with the trend of Wnt/ $\beta$-catenin pathway activation after alteration of Bmal1 and Per2. Therefore, Bmal1 and Per2 might negatively regulate the osteogenic differentiation of BMSCs through repression of the Wnt/ $\beta$-catenin pathway by downregulating Rora. Many studies have found that overexpression of Rora can suppress the expression of $\beta$-catenin in the nucleus and inhibit tumor growth, cancer cell proliferation and invasion by negatively regulating Wnt/ $\beta$-catenin signaling pathway activity. ${ }^{46.47}$ This seems to contradict our hypothesis that Rora can promote osteogenic differentiation by activating the Wnt/ $\beta$-catenin pathway. However, the understanding of the complexity of the Wnt/ $\beta$-catenin signaling network is ever growing, as it has multiple ligands and receptors, which may have cell-, tissue-, or stage-specific effects. ${ }^{48.49}$ Therefore, further research is needed to clarify the relationship between Rora and the Wnt/ $\beta$-catenin pathway. ${ }^{50}$ Our previous study found that Rev-erba could play a negative role in BMSCs during the late stage of osteogenesis by inhibiting the secretion of bone sialoprotein (BSP). Overexpression of Rev-erba inhibited the proliferation of BMSCs, and activating the Wnt/ $\beta$-catenin pathway could partially reverse the inhibition of cell proliferation caused by Rev-erba overexpression. This also supports that Rev-erba participates in the negative regulation of the osteogenic differentiation and proliferation of BMSCs and has some interaction with the Wnt/ $\beta$-catenin pathway. Our results showed that after alteration of Bmal1 and Per2 expression, the expression trend of Rev-erba was opposite to that of the Wnt/ $\beta$-catenin pathway activators. However, this conclusion needs to be verified by observing the changes in Wnt/ $\beta$-catenin signaling molecules after alteration of Rora and Rev-erba expression, which will be the goal of our follow-up research. 
5.1 Inhibiting the expression of Bmal1 or Per2 suppresses the proliferation of BMSCs in vitro, indicating that both of them have a positive effect on cell proliferation activation, showing synergistic effects on the aging of BMSCs, especially in terms of proliferation.

5.2 Bmal1 and Per2 play a synergistic role in negatively regulating the osteogenic differentiation of BMSCs.

5.3 Bmal1 and Per2 are involved in important processes, such as cell and molecular metabolism, and may take part in the regulation of the Wnt/ $\beta$-catenin pathway in an indirect way.

5.4 Bmal1 and Per2 may regulate the activation of the Wnt/ $\beta$-catenin pathway through Rora and Reverba, thus altering the osteogenic differentiation ability of BMSCs.

\section{Abbreviations}

BMSCs Bone Marrow Mesenchymal Stem

Bmal1 Brain and muscle arant-like-1

Per2 Period 2

Clock Circadian locomotor output cycles kaput

Cry Cryptochrome

RORa Retinoic Acid-Related Orphan

Rev-erb Retinoid-related orphan receptor a

PCR Polymerase chain reaction

RT-PCR Reverse Transcription polymerase chain

RT-qPCR Real-time fluorescence quantitative

FBS Fetal Bovine Serum

PBS phosphate-buffered saline

DMSO dimethyl sulfoxide

EDTA Ethylene Diamine Tetraacetic Acid

FCM flow cytometry

W/R wiectorn hlnt

Loading [MathJax]/jax/output/CommonHTML/jax.js 
SA- $\beta$-gal senescence-associated $\beta$-galactosidase

GFP Green fluorescent protein

RFP Red fluorescent protein

BSA Bovine Serum Albumin

MTT Methyl thiazolyl tetrazolium

CCGs circadian clock genes

Alp alkaline phosphatase

Ocn osteocalcin

Runx2 runt-related transcription factor 2

Wnt3a Wingless Int1 3a

C-myc Cell-myc1

TCF1 T-cell-specific transcription factor 1

P-GSK-3 Phosphorylated glycogen synthase kinase-3 $\beta$

ChIP-Seq chromatin immunoprecipitation and high-throughput sequencing

\section{Declarations}

\section{Ethics approval and consent to participate}

The Research Ethics Committee of State Key Laboratory of Oral Diseases reviewed our research project and made the resolution as the following: The experiment involved ethical part conforms to the scientific experiment ethical requirement, it is agreed to implement the experiment.

\section{Consent for publication}

Not applicable

\section{Availability of data and materials}

All datasets generated and/or analysed during this study are included in this published article [and its supplementary infoemation files].

\section{Competing interests}


The authors declare that they have no competing interests.

\section{Funding}

This work was supported by the National Science Foundation of China (no. 81870745 and no.81371113).

\section{Authors' contributions}

Jiawen Zheng and Lanxin Zhang designed the projects, acquired the data and wrote the manuscript. Qing Zhao and Zhen Tan designed the projects and approved the draft. Xiaoyu Wei and Yuqing Yang constructed the figures and approved the draft. Yuhong Wang and Chengxiaoxue Zhang interpreted the data and approved the draft.

\section{Acknowledgements}

Not applicable

\section{References}

1. Chen, H. T.; Lee, M.-J.; Chen, C.-H.; Chuang, S.-C.; Chang, L.-F.; Ho, M.-L.; Hung, S.-H.; Fu, Y.-C.; Wang, Y.H.; Wang, H.-I., Proliferation and differentiation potential of human adipose-derived mesenchymal stem cells isolated from elderly patients with osteoporotic fractures. Journal of Cellular \& Molecular Medicine 2012,16 (3), 582-592.

2. Luo, Z.; Liu, M.; Sun, L.; Rui, F., Icariin recovers the osteogenic differentiation and bone formation of bone marrow stromal cells from a rat model of estrogen deficiency-induced osteoporosis. Molecular Medicine Reports 2015,12 (1), 382-388.

3. Kondratov; V., R., Early aging and age-related pathologies in mice deficient in BMAL1, the core componentof the circadian clock. Genes \& Development 2006,20 (14), 1868-1873.

4. Mcdearmon, E. L.; Patel, K. N.; Ko, C. H.; Walisser, J. A.; Schook, A. C.; Chong, J. L.; Wilsbacher, L. D.; Song, E. J.; Hong, H.-K.; Bradfield, C. A., Dissecting the Functions of the Mammalian Clock Protein BMAL1 by Tissue-Specific Rescue in Mice. Science 2006,314 (5803), 1304-1308.

5. Buhr, E. D.; Takahashi, J. S., Molecular components of the Mammalian circadian clock. 2013,15 Spec No 2 (217), 3.

6. Hood, S.; Amir, S., The aging clock: circadian rhythms and later life. Journal of Clinical Investigation 2017, $127(2), 437-446$.

7. Onoue, T.; Nishi, G.; Hikima, J.; Sakai, M.; Kono, T., Circadian oscillation of TNF-alpha gene expression regulated by clock gene, BMAL1 and CLOCK1, in the Japanese medaka (Oryzias latipes). Int. Immunopharmacol. 2019,70, 362-371.

8. Dubrovsky, Y. V.; Samsa, W. E.; Kondratov, R. V., Deficiency of circadian protein CLOCK reduces ract development in mice. Aging-Us 2010,2 (12), 936-944. 
9. Lin, F.; Chen, Y.; Li, X.; Zhao, Q.; Tan, Z., Over-expression of circadian clock gene Bmal1 affects proliferation and the canonical Wnt pathway in NIH-3T3 cells. Cell Biochemistry and Function 2013,31 (2), 166-172.

10. Maronde, E.; Schilling, A. F.; Seitz, S.; Schinke, T.; Schmutz, I.; van der Horst, G.; Amling, M.; Albrecht, U., The Clock Genes Period 2 and Cryptochrome 2 Differentially Balance Bone Formation. Plos One 2010,5(7).

11. Takarada, T.; Xu, C.; Ochi, H.; Nakazato, R.; Yamada, D.; Nakamura, S.; Kodama, A.; Shimba, S.; Mieda, M.; Fukasawa, K.; Ozaki, K.; lezaki, T.; Fujikawa, K.; Yoneda, Y.; Numano, R.; Hida, A.; Tei, H.; Takeda, S.; Hinoi, E., Bone Resorption Is Regulated by Circadian Clock in Osteoblasts. J. Bone Miner. Res. 2017,32 (4), 872-881.

12. Al-Nuaimi, Y.; Hardman, J. A.; Biro, T.; Haslam, I. S.; Philpott, M. P.; Toth, B. I.; Farjo, N.; Farjo, B.; Baier, G.; Watson, R. E. B.; Grimaldi, B.; Kloepper, J. E.; Paus, R., A Meeting of Two Chronobiological Systems: Circadian Proteins Period1 and BMAL1 Modulate the Human Hair Cycle Clock. J. Invest. Dermatol. 2014,134 (3), 610-619.

13. Guo, B. Y.; Chatterjee, S.; Li, L. F.; Kim, J. M.; Lee, J.; Yechoor, V. K.; Minze, L. J.; Hsueh, W.; Ma, K., The clock gene, brain and muscle Arnt-like 1, regulates adipogenesis via Wnt signaling pathway. Faseb J. 2012,26 (8), 3453-3463.

14. Bajada, S.; Marshall, M. J.; Wright, K. T.; Richardson, J. B.; Johnson, W. E. B., Decreased osteogenesis, increased cell senescence and elevated Dickkopf-1 secretion in human fracture non union stromal cells. Bone 2009,45 (4), 726-735.

15. Rey, G.; Cesbron, F.; Rougemont, J.; Reinke, H.; Brunner, M.; Naef, F., Genome-Wide and Phase-Specific DNA-Binding Rhythms of BMAL1 Control Circadian Output Functions in Mouse Liver. Plos Biology 2011,9 (2).

16. Lee, J. M.; Kim, I. S.; Kim, H.; Lee, J. S.; Kim, K.; Yim, H. Y.; Jeong, J.; Kim, J. H.; Kim, J.-Y.; Lee, H.; Seo, S.-B.; Kim, H.; Rosenfeld, M. G.; Kim, K. I.; Baek, S. H., ROR alpha Attenuates Wnt/beta-Catenin Signaling by PKC alpha-Dependent Phosphorylation in Colon Cancer. Molecular Cell 2010,37 (2), 183-195.

17. Shimozaki, S.; Yamamoto, N.; Domoto, T.; Nishida, H.; Hayashi, K.; Kimura, H.; Takeuchi, A.; Miwa, S.; Igarashi, K.; Kato, T.; Aoki, Y.; Higuchi, T.; Hirose, M.; Hoffman, R. M.; Minamoto, T.; Tsuchiya, H., Efficacy of glycogen synthase kinase-3 beta targeting against osteosarcoma via activation of betacatenin. Oncotarget 2016,7 (47), 77038-77051.

18. Zhuo, H.; Wang, Y.; Zhao, Q., The Interaction between Bmal1 and Per2 in Mouse BMSC Osteogenic Differentiation. Stem Cells International 2018.

19. Chen, J.; Long, F., mTOR signaling in skeletal development and disease. Bone Research 2018,6.

20. Boucher, H.; Vanneaux, V.; Domet, T.; Parouchev, A.; Larghero, J., Circadian Clock Genes Modulate Human Bone Marrow Mesenchymal Stem Cell Differentiation, Migration and Cell Cycle. Plos One 2016, 11 (1), e0146674. 
21. Cadigan, K. M.; Waterman, M. L., TCF/LEFs and Wnt Signaling in the Nucleus. Cold Spring Harbor Perspectives in Biology 2012, 4 (11), a007906-a007906.

22. He Y, Lin F, Chen Y, et al. Overexpression of the Circadian Clock Gene Reverbalpha Affects Murine Bone Mesenchymal Stem Cell Proliferation. Osteogenesis. Stem Cells Dev 2015;24(10):1194-204.

23. DiLoreto, R.; Murphy, C. T., The cell biology of aging. Molecular Biology of the Cell 2015, 26 (25), 4524-4531.

24. Boucher, H; Vanneaux, V; Domet, T.; Parouchev, A; Larghero, J, Circadian Clock Genes Modulate Human Bone Marrow Mesenchymal Stem Cell Differentiation, Migration and Cell Cycle. Plos One 2016, 11 (1), e0146674.

25. LI Ying, LIU Na, ZHANG Wei. Effects of canonical Wnt/ $\beta$-catenin over expression on proliferation and osteogenic differentiation of human periodontal ligament stem cells[J]. chinese journal of geriatric dentistry, 2017.

26. Ge X, Shi R, Ma X. The secreted protein WNT5A regulates condylar chondrocyte proliferation, hypertrophy and migration[J]. Archives of Oral Biology, 2017:S0003996917301966.

27. DeCarolis NA, Wharton KA, Jr., Eisch AJ. Which way does the Wnt blow? Exploring the duality of canonical Wnt signaling on cellular aging. Bioessays. 2008;30(2):102-6.

28. Klaus A, Saga Y, Taketo MM, Tzahor E, Birchmeier W. Distinct roles of Wnt/beta-catenin and Bmp signaling during early cardiogenesis. Proc Natl Acad Sci U S A. 2007;104(47):18531-6..

29. Shimozaki, S.; Yamamoto, N.; Domoto, T.; Nishida, H.; Hayashi, K.; Kimura, H.; Takeuchi, A.; Miwa, S.; Igarashi, K.; Kato, T.; Aoki, Y.; Higuchi, T.; Hirose, M.; Hoffman, R. M.; Minamoto, T.; Tsuchiya, H., Efficacy of glycogen synthase kinase-3 beta targeting against osteosarcoma via activation of betacatenin. Oncotarget 2016, 7 (47), 77038-77051.

30. K., I. M. M., A molecular mechanism that links Hippo signalling to the inhibition of Wnt/[[beta]|catenin signalling. 2012.

31. Kim, M.; Jho, E. H., Cross-talk between Wnt/beta-catenin and Hippo signaling pathways: a brief review. BMB Rep. 2014, 47 (10), 540-545.

32. Azzolin, L.; Panciera, T.; Soligo, S.; Enzo, E.; Bicciato, S.; Dupont, S.; Bresolin, S.; Frasson, C.; Basso, G.; Guzzardo, V.; Fassina, A.; Cordenonsi, M.; Piccolo, S., YAP/TAZ Incorporation in the beta-Catenin Destruction Complex Orchestrates the Wnt Response. Cell 2014, 158 (1), 157-170.

33. Park, H. W.; Kim, Y. C.; Yu, B.; Moroishi, T.; Mo, J. S.; Plouffe, S. W.; Meng, Z. P.; Lin, K. C.; Yu, F. X.; Alexander, C. M.; Wang, C. Y.; Guan, K. L., Alternative Wnt Signaling Activates YAP/TAZ. Cell 2015, 162 (4), 780-794.

34. Chen, J.; Long, F., mTOR signaling in skeletal development and disease. Bone Research 2018, 6. 35. M, K.; D, M.; Neoplasia, S. A. J., Attenuation of Tumor Suppressive Function of FBXO16 Ubiquitin Ligase Activates Wnt Signaling In Glioblastoma. 2019, 21 (1), 106-116.

36. Jager, J.; Wang, F.; Fang, B.; Lim, H.-W.; Peed, L. C.; Steger, D. J.; Won, K.-J.; Kharitonenkov, A.; Adams, A. C.; Lazar, M. A., The Nuclear Receptor Rev-erb alpha Regulates Adipose Tissue-specific FGF21 Loading [MathJax]/jax/output/CommonHTML/jax.js 
Signaling. Journal of Biological Chemistry 2016, 291 (20), 10867-10875.

37. Shimozaki, S.; Yamamoto, N.; Domoto, T.; Nishida, H.; Hayashi, K.; Kimura, H.; Takeuchi, A.; Miwa, S.; Igarashi, K.; Kato, T.; Aoki, Y.; Higuchi, T.; Hirose, M.; Hoffman, R. M.; Minamoto, T.; Tsuchiya, H., Efficacy of glycogen synthase kinase-3 beta targeting against osteosarcoma via activation of betacatenin. Oncotarget 2016, 7 (47), 77038-77051.

38. Lee, J. M.; Kim, I. S.; Kim, H.; Lee, J. S.; Kim, K.; Yim, H. Y.; Jeong, J.; Kim, J. H.; Kim, J.-Y.; Lee, H.; Seo, S.-B.; Kim, H.; Rosenfeld, M. G.; Kim, K. I.; Baek, S. H., ROR alpha Attenuates Wnt/beta-Catenin Signalin

39. Teboul, M.; Delaunay, F., The orphan nuclear receptor Rev-erb alpha is a major component of the circadian clock. M S-Medecine Sciences 2003, 19 (4), 411-413.

40. Estradiol-induced RORa expression positively regulates osteoblast differentiation.2019

41. Retinoic Acid Receptor-Related Receptor Alpha Ameliorates Autoimmune Arthritis via Inhibiting of Th17 Cells and Osteoclastogenesis 2019.

42. Salehi, M.; Kamali, E.; Karahmadi, M.; Mousavi, S. M., RORA and Autism in Isfahan Population: Is There An Epigenetic Relationship. Cell Journal 2017, 18 (4),

43. Green, A. C.; Martin, T. J.; Purton, L. E., The role of vitamin A and retinoic acid receptor signaling in post-natal maintenance of bone. Journal of Steroid Biochemistry and Molecular Biology 2016, 155, 135-146.

44. Meyer, T.; Kneissel, M.; Mariani, J.; Fournier, B., In vitro and in vivo evidence for orphan nuclear receptor ROR alpha function in bone metabolism. Proceedings of the National Academy of Sciences of the United States of America 2000, 97 (16), 9197-+.

45. Yang, N.; Meng, Q.-J., Circadian Clocks in Articular Cartilage and Bone: A Compass in the Sea of Matrices. Journal of Biological Rhythms 2016, 31 (5), 415-427.

46. RORa Suppresses Epithelial-to-Mesenchymal Transition and Invasion in Human Gastric Cancer Cells via the Wnt/ $\beta$-Catenin Pathway 2019

47. N-Terminal Domain Mediated Regulation of RORa1 Inhibits Invasive Growth in Prostate Cancer 2019

48. Which way does the Wnt blow? Exploring the duality of canonical Wnt signaling on cellular aging 2008

49. Beta-Catenin Signaling Plays a Disparate Role in Different Phases of Fracture Repair: Implications for Therapy to Improve Bone Healing 2007

50. Rev-erba Negatively Regulates Osteoclast and Osteoblast Differentiation through p38 MAPK Signaling Pathway 2020

51. Chatterjee, S.; Ma, K., Circadian clock regulation of skeletal muscle growth and repair. F1000Research 2016, 5, 1549-1549.

52. Fontaine, C.; Dubois, G.; Duguay, Y.; Helledie, T.; Vu-Dac, N.; Gervois, P.; Soncin, F.; Mandrup, S.; Fruchart, J. C.; Fruchart-Najib, J.; Staels, B., The orphan nuclear receptor Rev-Erb alpha is a 
peroxisome proliferator-activated receptor (PPAR) gamma target gene and promotes PPAR gammainduced adipocyte differentiation. Journal of Biological Chemistry 2003, 278 (39), 37672-37680.

\section{Figures}

(A)

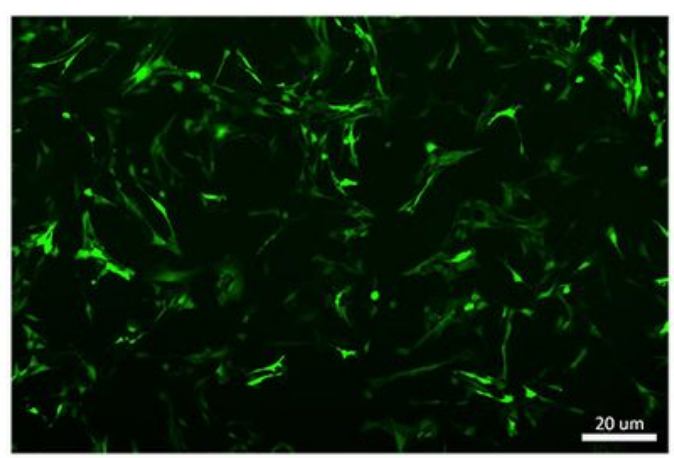

GFP

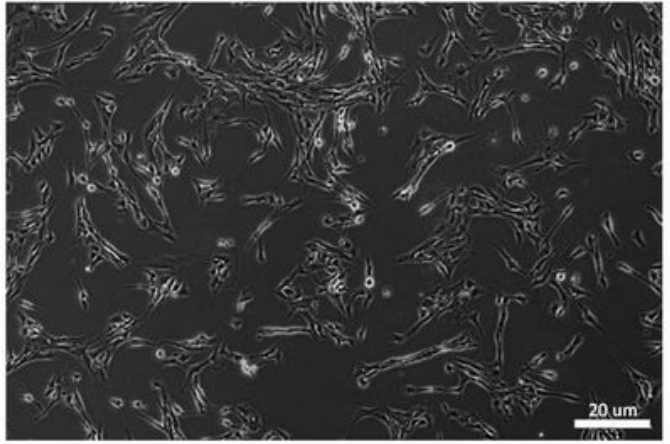

Light

(C)

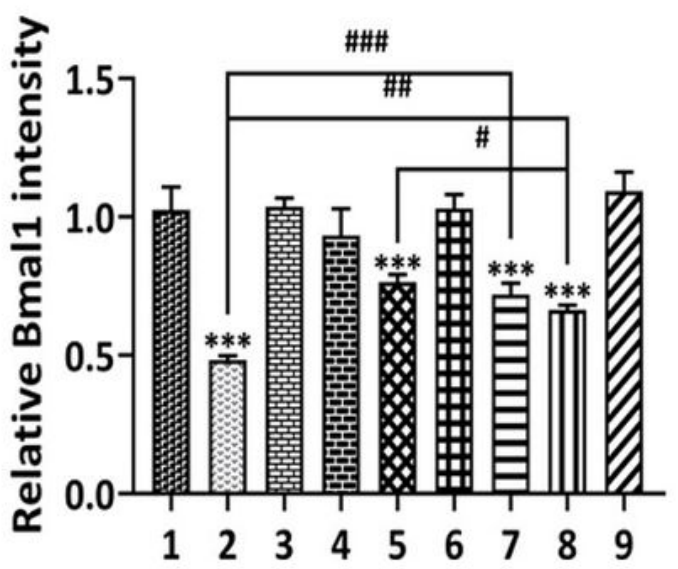

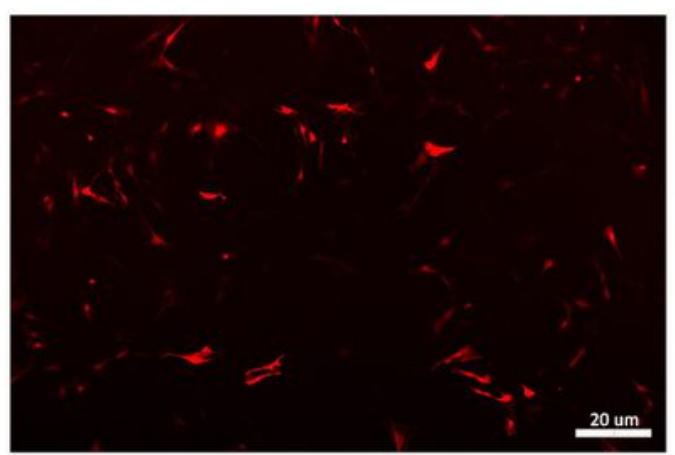

RFP

(B)

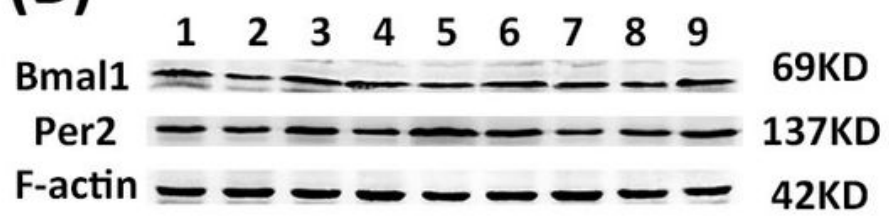

Figure 1

Figure 1 
The protein expression of Bmal1 and Per2 after viral transfection and the fluorescence intensity. A, The green and red fluorescence was observed 48 hours after BMSC transfection with the Bmal1 shRNA lentivirus (LV-Bmal1 shRNA) and the Per2 shRNA adenovirus (AD-Per2 shRNA) Magnification is 100x. B, C, The protein expression level of Bmal1 and Per2 in the BMSCs 48 hours after viral transfection.

Numbers 1, 2, 3, 4, 5, 6, 7, 8, and 9 represent the empty, Bmal1 inhibition, Bmal1 empty, Per2 inhibition, Per2 overexpression, Per2 empty, Bmal1 inhibition/Per2 inhibition, Bmal1 inhibition/Per2 overexpression, and Bmal1 empty/Per2 empty groups, respectively. The protein expression level of Bmal1 and Per2 were well altered compared to the control groups. Asterisks indicate the statistical difference of a group compared to the level in the control groups: group $1,3,6$ and $9(\star \star \star P<0.001)$. Pound signs represent the statistical difference between two groups ( $\# P<0.05$, \#\#P<0.01, \#\#\#P<0.001). 

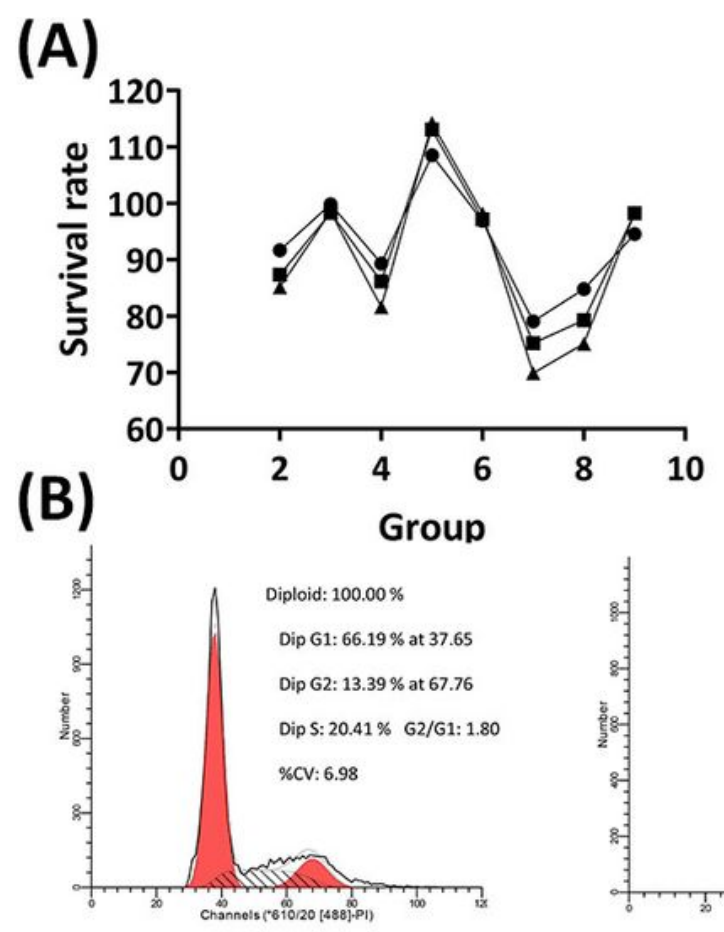

Group 1

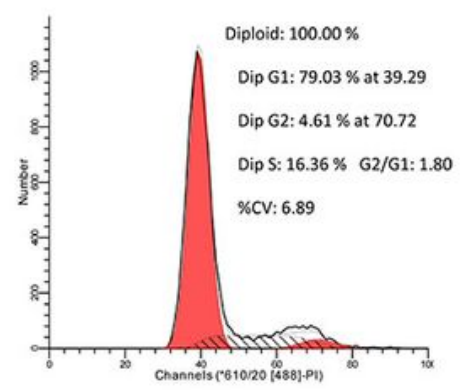

Group 4

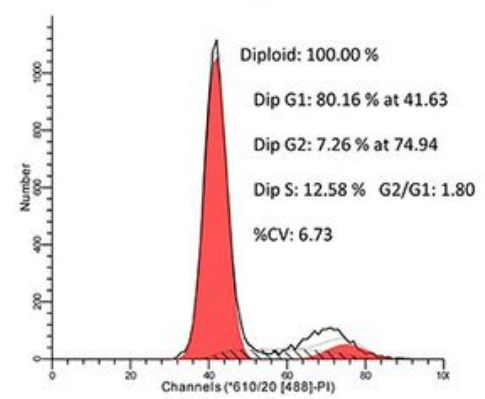

Group 7

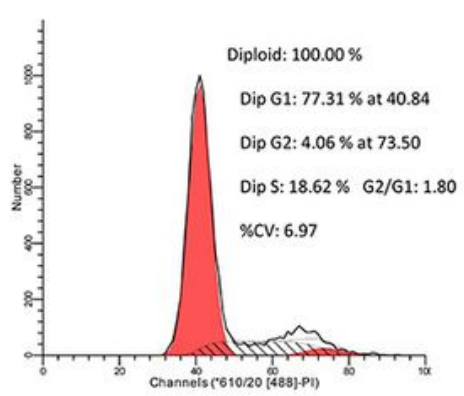

Group 2

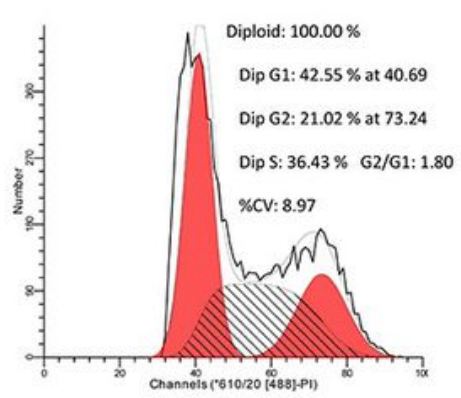

Group 5

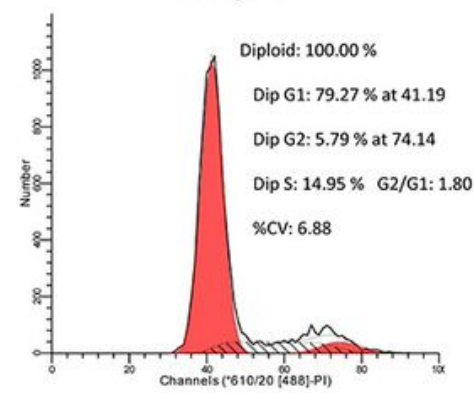

Group 8

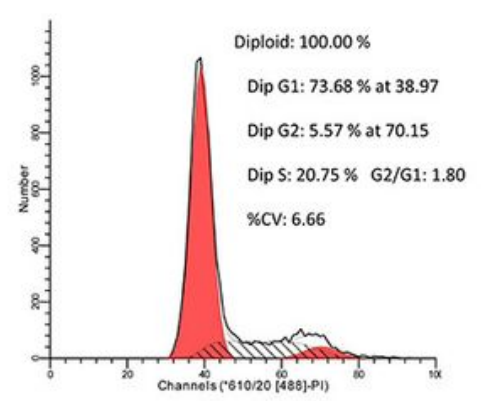

Group 3

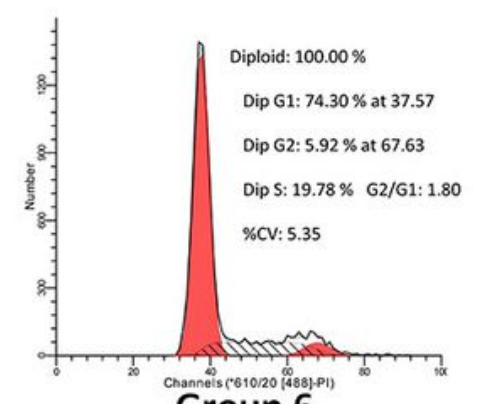

Group 6

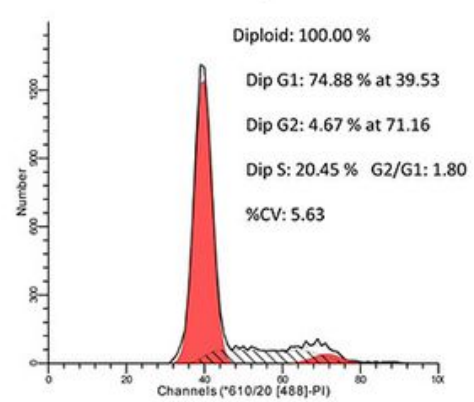

Group 9

\section{Figure 2}

\section{Figure 2}

A, The survival rate was calculated with OD490 values obtained by MTT assays performed 24 hours, 48 hours and 72 hours after transfection compared with BMSCs transfected with empty viral vectors (groups 3,6 , and 9), vector suppressing Bmal1 (brain and muscle Arnt-like protein-1) (group 2), vector suppressing Per2 (Period-2) (group 4) or vector suppressing both Bmal1 and Per2 (group 7), the proliferation rate was Loading [MathJax]/jax/output/CommonHTML/jax.js ? (group 5) increased proliferation activity. B, The cell cycle 
distribution of the 9 groups. The survival rate was calculated with OD490 values 24 hours, 48 hours and 72 hours after transfection as determined by MTT assay. Compared with BMSCs transfected with empty virus (groups 3,6, and 9), BMSCs transfected with the Bmal1-suppressing vector (group 2), Per2suppressing vector (group 4) or both (group 7), the proliferation rate was significantly decreased. The cells overexpressing Per2 (group 5) had increased proliferation activity.

(A)
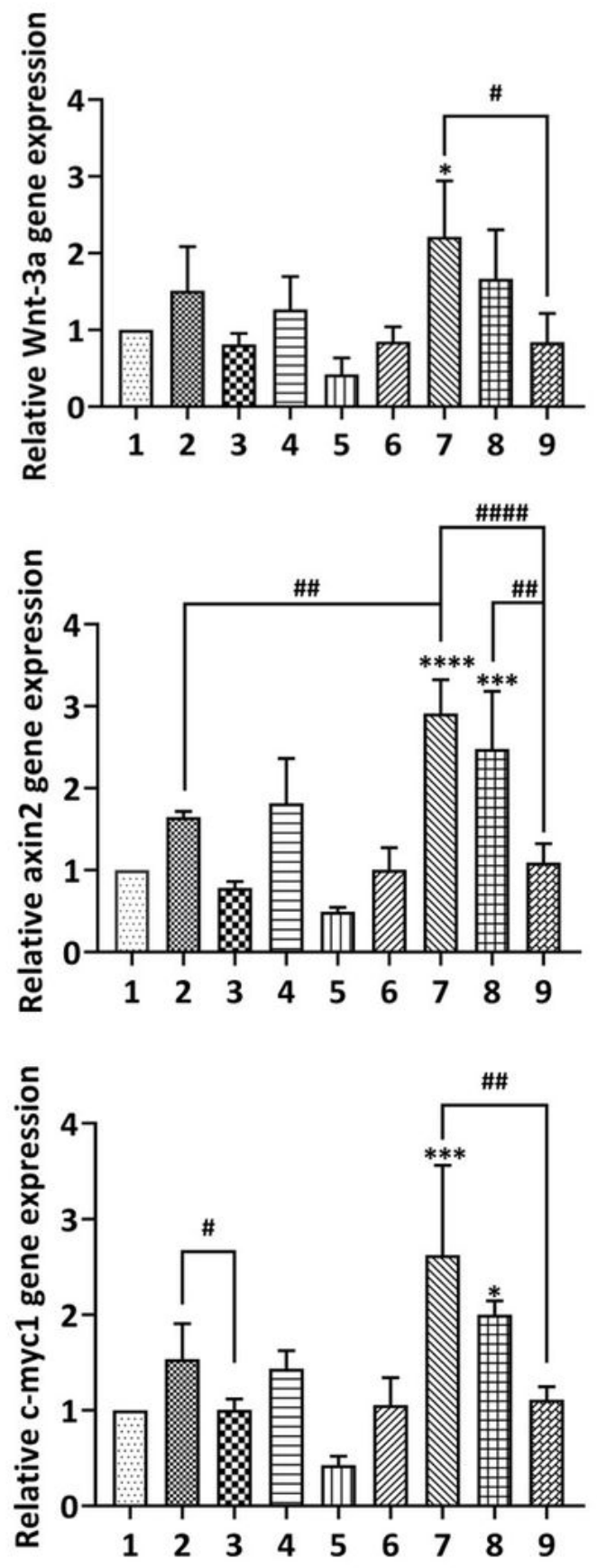

(B)
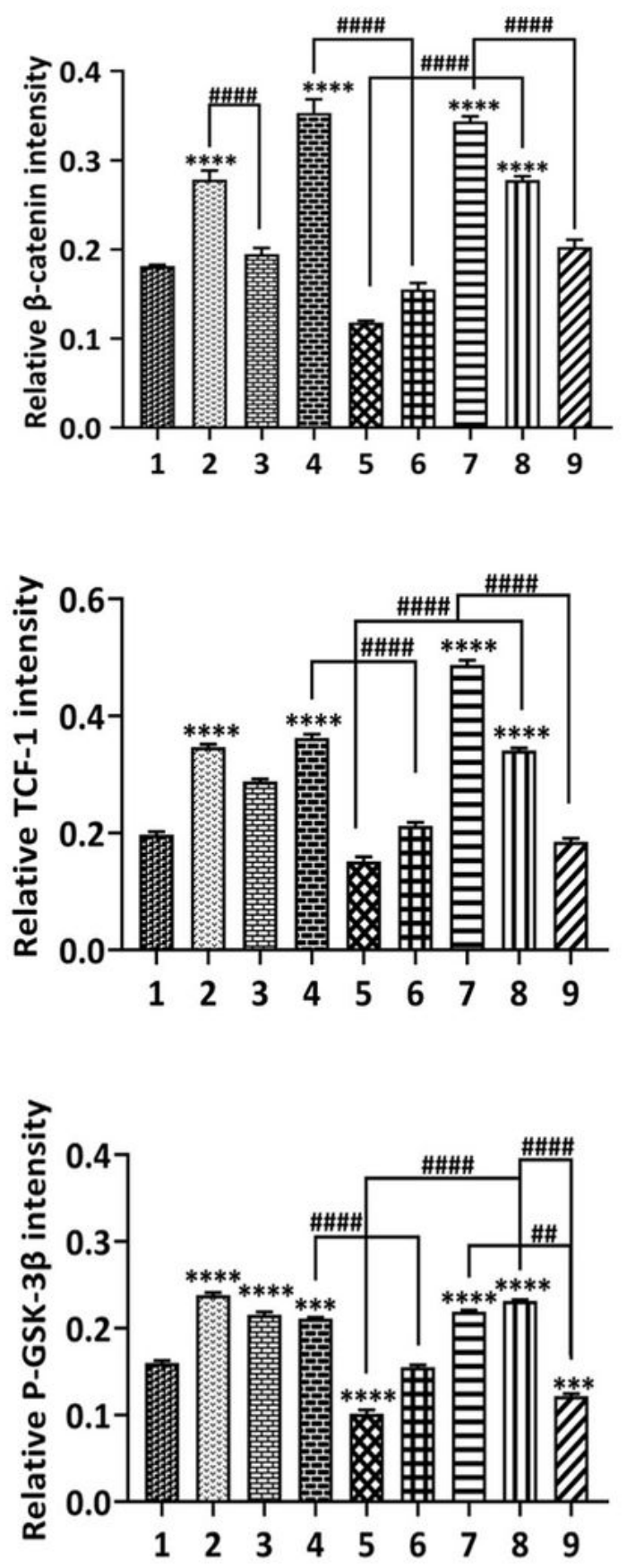

(d)

Figure 3

Figure 3 
A, The mRNA expression levels of Wnt-3a (Wingless Int1 3a), c-myc1 (Cell-myc1) and axin2, which are all $W n t / \beta$-catenin signaling pathway-related genes. The values are expressed as the means \pm SD of at least

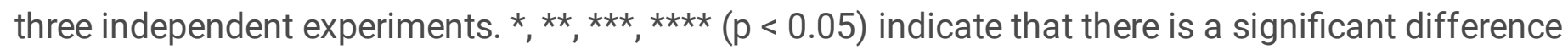

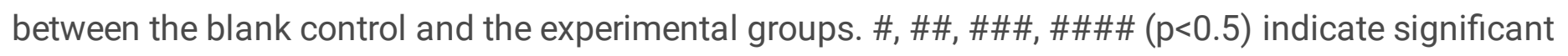
differences between experimental groups. $B$, and FIGURE 2 C, Western blot showing the protein levels of $\beta$-catenin, TCF-1 (T-cell-specific transcription factor1), and P-GSK-3 $\beta$ (Phosphorylated glycogen synthase kinase-3 $\beta$ ) with GAPDH (Glyceraldehyde-3-phosphate dehydrogenase) serving as an internal reference. The protein level is represented by the ratio of expression level with respect to the internal reference. ${ }^{*}, * \star$,

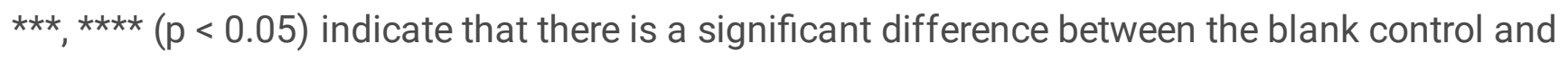
experimental groups. \#, \#\#, \#\#\#, \#\#\# ( $<<0.5)$ indicate significant differences between experimental groups. 
(A)
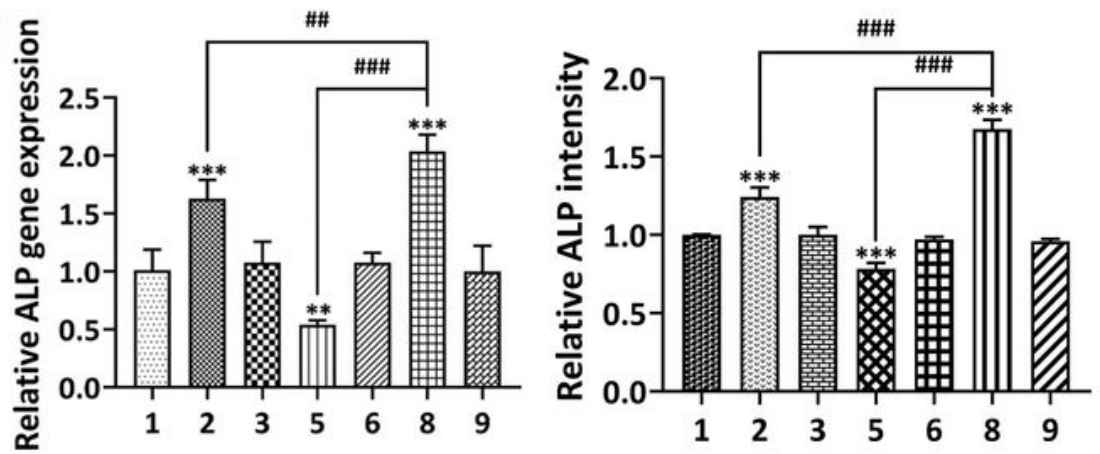

(B)
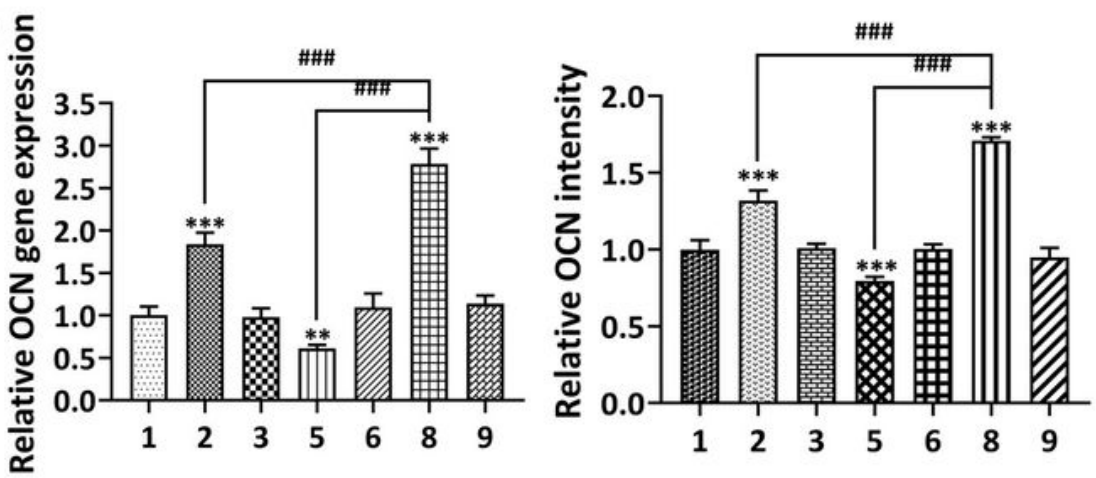

(C)
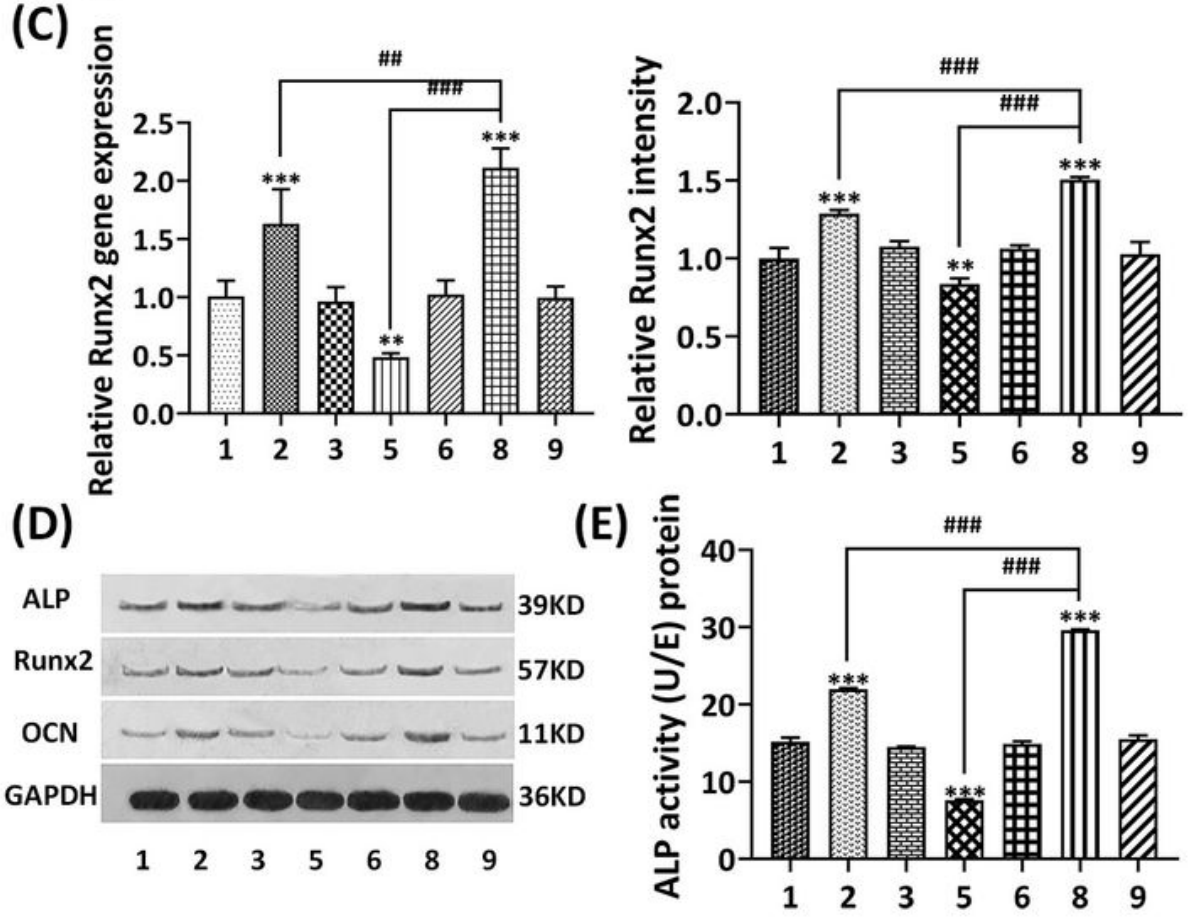

Figure 4

\section{Figure 4}

The mRNA and protein expression of ALP (Alkaline phosphatase), Runx2 (Runt related transcription factor2) and OCN (Osteocalcin) in BMSCs 7 days after osteogenic induction. A, ALP mRNA expression and intensity; B, OCN mRNA expression and intensity; C, Runx2 mRNA expression and intensity. D, The result of Western blotting. GAPDH (Glyceraldehyde-3-phosphate dehydrogenase) was the internal 
the ratio of ALP, RUNX2 and OCN to GAPDH. E, The activity of ALP in 7 groups after 7 days of osteogenic induction. Data are presented as the means $\pm S D(n=3)$. Asterisks indicate the significant difference of a group compared to the level of the control groups: group $1,3,6$ and $9\left({ }^{*} P<0.01\right.$, and $\left.{ }^{*} * *<0.001\right)$. Pound signs represent the significant difference between two groups (\#\#P<0.01 and \#\#\#P<0.001).
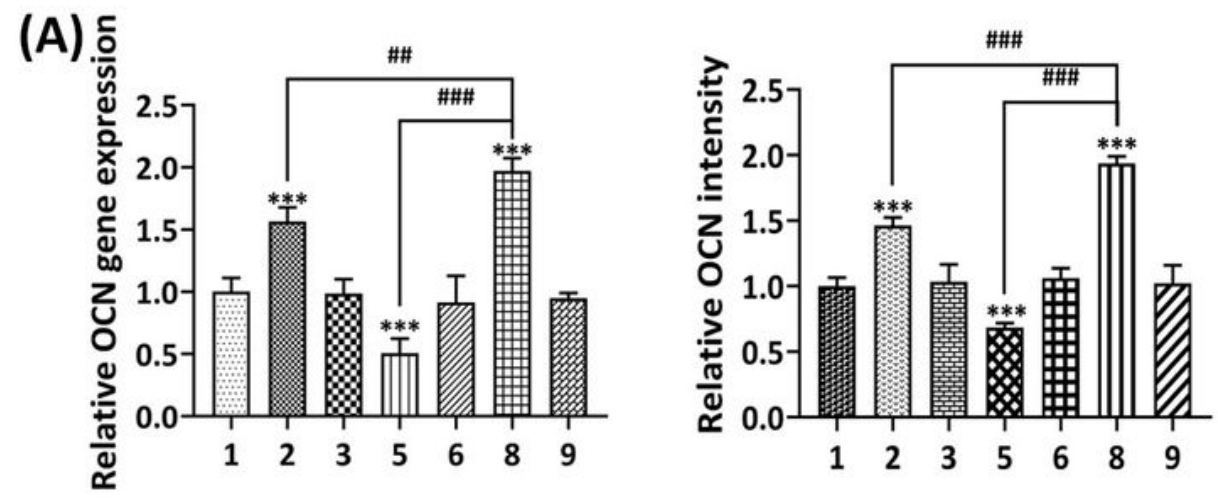

(B)

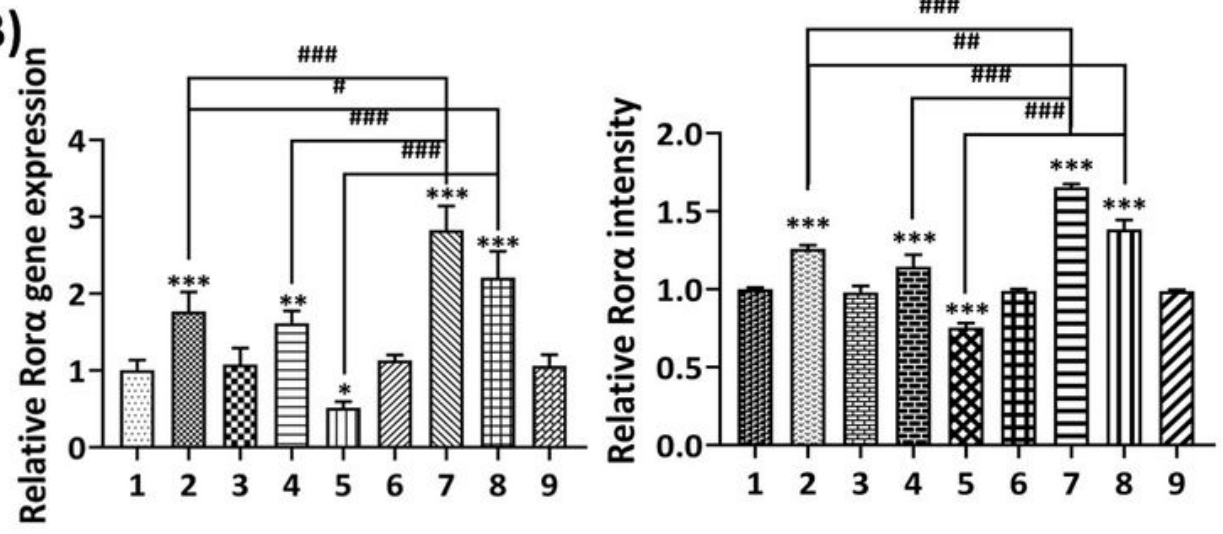

(C) $\div$ 흔

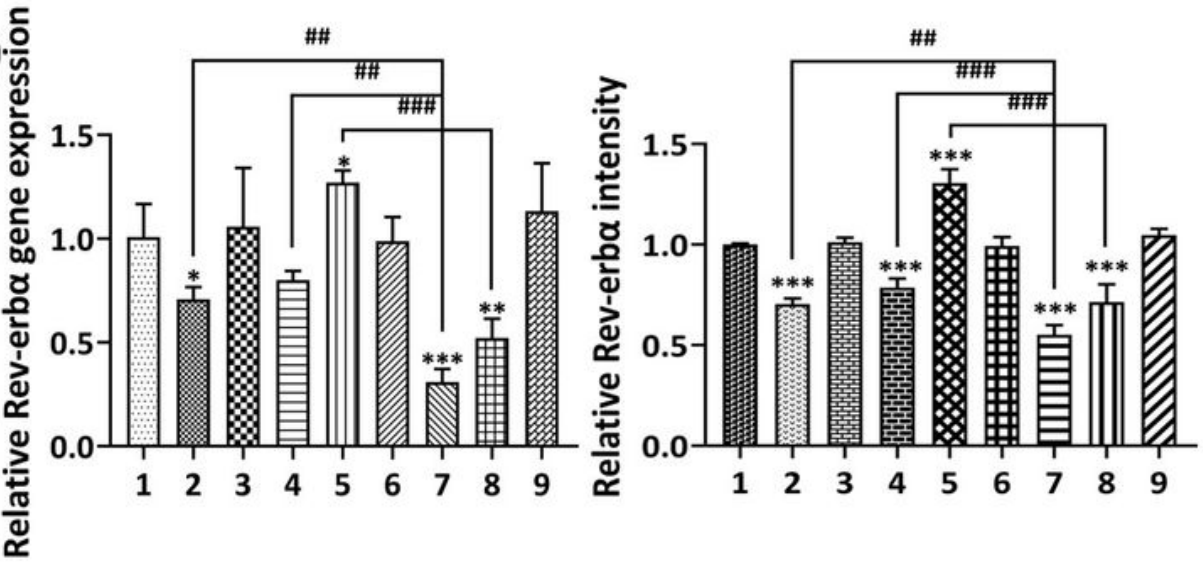

(D)

(E)

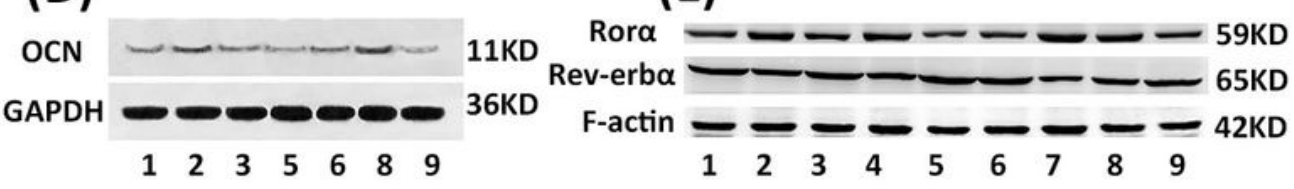

Figure 5

Figure 5 
A, mRNA and protein expression of OCN (Osteocalcin) in 7 groups after 14 days of osteogenic induction. $B, C$, The mRNA and protein expression of Rora (Retinoid acid receptor related orphan receptor $a$ ) and Reverba after viral transfection of the BMSCs. The Western blotting results of Rora and Rev-erba expression among all groups showing the same trend as the expression of mRNA. F-actin was the internal reference. $D, E$, Western blot results. Densitometry was utilized to quantify the protein expression levels, which were determined by the ratio of RORa and REV-ERBa, respectively, to F-actin. Data are presented as the means $\pm S D(n=3)$. Asterisks indicate the statistical difference of a group compared to the level in the control groups: group $1,3,6$ and $9\left({ }^{*} P<0.05,{ }^{*} P<00.01,{ }^{*} * P<0.001\right)$. Pound signs represent the statistical difference between two groups (\#P<0.05, \#\#P<0.01, \#\#\#P<0.001).

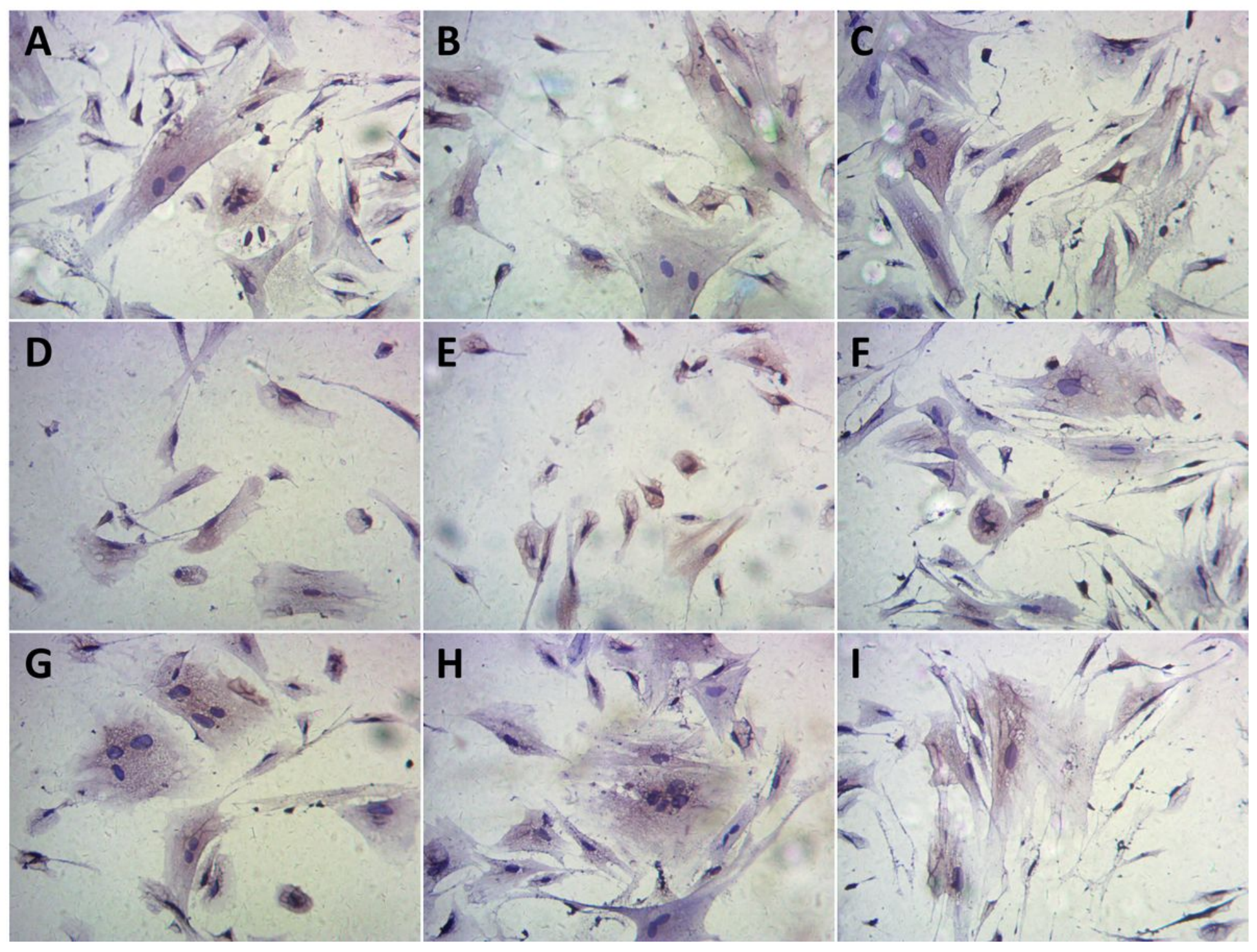

\section{Figure 6}

The immunohistochemistry results of ALP. A-I represent 9 groups respectively. 


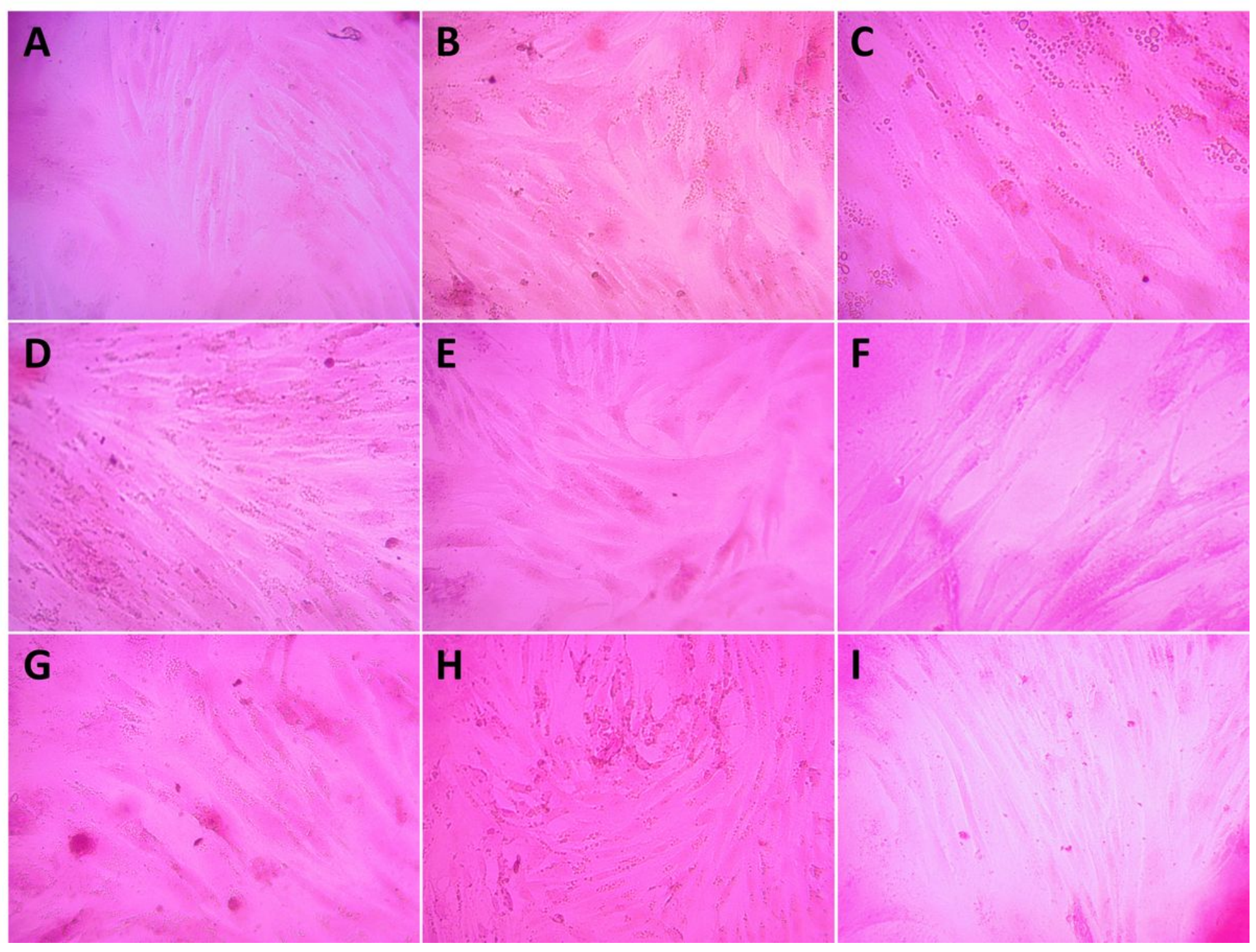

Figure 7

The alizarin red staining results after osteogenic induction 14 days . A-I represent 9 groups respectively. 


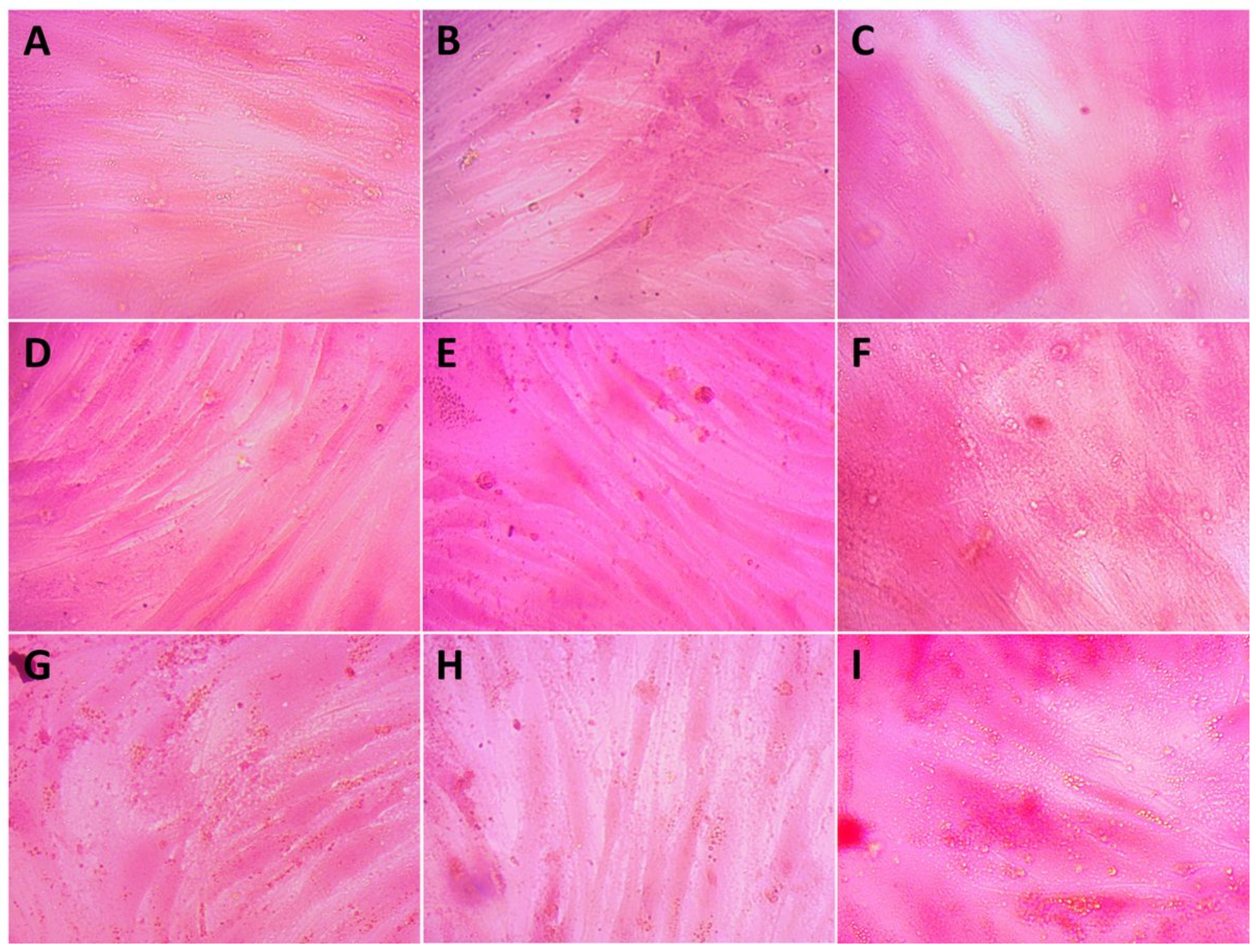

\section{Figure 8}

The alizarin red staining results after osteogenic induction 21 days. A-I represent 9 groups respectively. 
(A)

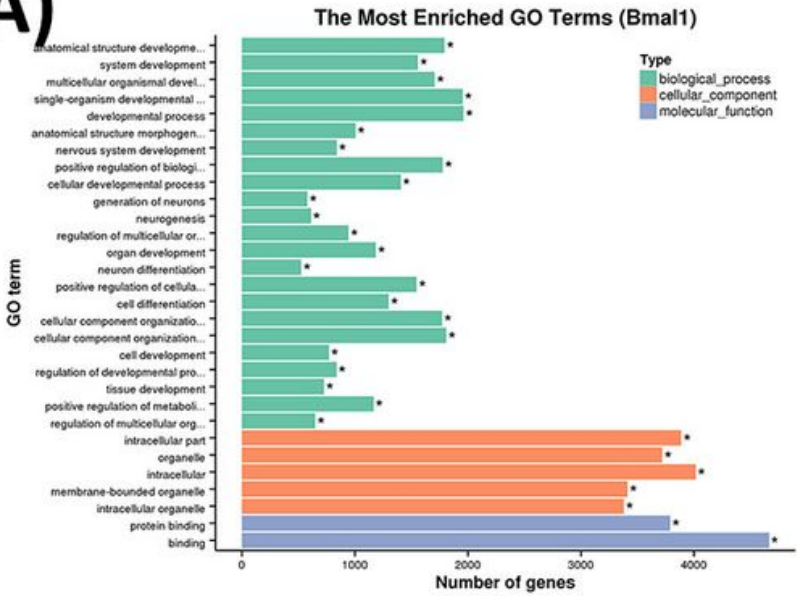

(C)

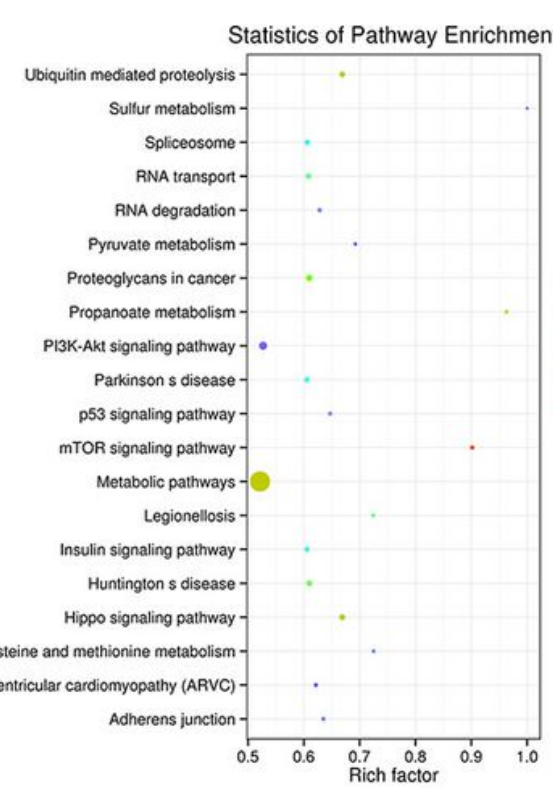

(B)

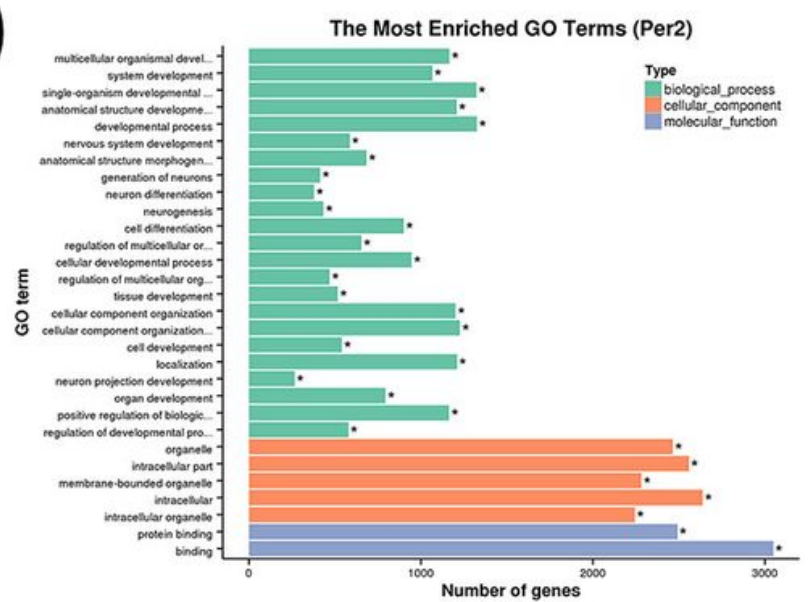

(D)

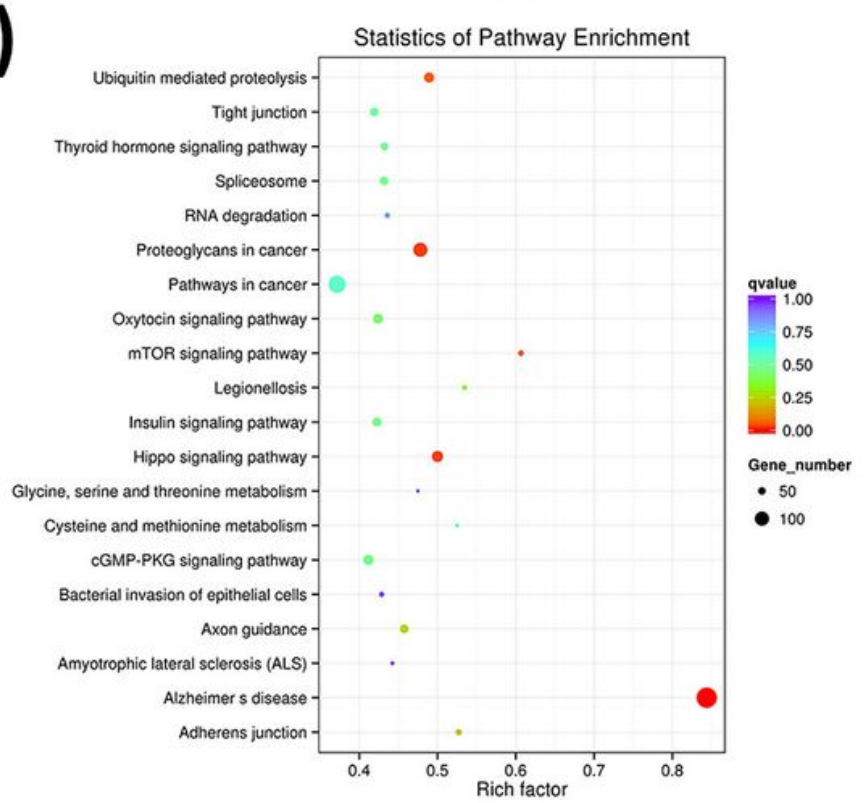

\section{Figure 9}

A, The results from the GO enrichment analysis of Bmal1 (brain and muscle Arnt-like protein-1), with the number on the $\mathrm{X}$-axis representing the number of overlapping gene peaks. Different colors are used to differentiate biological processes, cellular components and molecular functions. B, Results from the GO enrichment analysis of Per2 (Period-2). C,D, Results from the KEGG analysis of Bmal1 and Per2. The names of the pathways are listed on the $Y$-axis, while the values of the enriched factors are listed on the $\mathrm{X}$-axis. The dot size indicates the number of overlapping genes in this pathway, while dot color represents the different range of q-value.

\section{Supplementary Files}

This is a list of supplementary files associated with this preprint. Click to download.

- GraphicalAbstract.docx 